\title{
Herd Mentality in the Stock Market: \\ On the Role of Idiosyncratic Participants with Heterogeneous Information
}

\author{
Ha V. Dang \\ University of Lincoln
}

\author{
Mi Lin \\ University of Lincoln
}

This version: 24 September 2016

\begin{abstract}
This paper examines herd behaviour using aggregate market data for stocks, with a focus on the role of idiosyncratic participants with heterogeneous information. We look at herding asymmetry between up and down markets, taking into consideration the daily price limits and the impact of the recent financial crisis. We also improve upon existing tests for fundamental and non-fundamental herding, as well as proposing a method for investigating herd behaviour of different groups of investors. Empirical evidence based on the Ho Chi Minh Stock Exchange in Vietnam reveals a greater level of herding on up compared to down market days, and a significant reduction in the magnitude of herding following the crisis. We document robust intentional herding even when unintentional (fundamental) herding is factored out. Our empirical results also uncover potential within-group herding and between-group interactions among arbitrageurs and noise traders in the market.
\end{abstract}

Key Words: Herd Behaviour, Behavioural Finance, Financial Crises, Stock Markets.

JEL Classification: G01, G02, G11. 


\section{Introduction}

Herding towards the stock market consensus has been receiving great attention from both academics and policy makers. In the existence of herding, a group of investors tend to trade in the same direction over a period of time, leading to observed behaviour patterns that are correlated across individuals (Bikhchandani et al., 1992), which is an undesirable consequence for risk diversification. As another major consequence of herding, if market participants tend to herd around the market consensus, investors' trading behaviour can cause asset prices to deviate from their fundamentals, resulting in assets being inappropriately priced. Herding thus is of considerable concern to market participants, as it could cause investors to transact at inefficient prices (Fama, 1970; Christie \& Huang, 1995), increase difficulty for investors in performing diversification (Chang et al., 2000; Venezia et al., 2011), and accelerate financial market volatility and instability (Bikhchandani \& Sharma, 2001).

Empirical literature on herd behaviour is generally categorised into two main strands. The first strand relies on detailed investor-specific data to detect herding by institutional investors in the form of correlation in trading patterns among a particular group of investors, usually fund managers (see, among others, Lakonishok et al., 1992; Grinblatt et al., 1995; Wermers, 1999; and Frey et al., 2014). The second strand makes use of aggregate market data and aims at uncovering co-movements towards the market consensus due to individual investors' behaviour (see, among others, Christie \& Huang, 1995; Chang et al., 2000; Galariotis et al., 2015). This paper falls within the second strand, testing for herding towards the market consensus with a focus of further exploring the role of idiosyncratic investors with heterogeneous information.

Evidence documented in the literature indicates that herd behaviour is more likely to occur in emerging markets, where there might not be many experienced market participants and the governing rules regarding the release and the flow of information are limited, leading to diverse responses and interactions among idiosyncratic investors when they are exposed to heterogeneous information. For instance, investors might act differently in the process of collecting and analysing information. Less sophisticated investors may find it costly to collect and analyse information on their own, and therefore tend to mimic what more successful 
investors do (Villatoro, 2009; Chiang \& Zheng, 2010). Trading with heterogeneous information due to information asymmetry also plays a major role in creating herds. Bikhchandani and Sharma (2001) argue that, under the situation of information asymmetry, some investors might supress their own sets of private information and turn to follow others' behaviour due to intrinsic preference for conformity. When investors do not make their investment decisions simultaneously, such information cascades could easily turn into so-called intentional herding. Moreover, when investors are faced with inadequate supply of firm-specific information, which is likely to happen in emerging markets, they might resort to using solely macroeconomic information, resulting in similar investment decisions when facing similar decision problems with similar information sets (such as fundamental information regarding the macro economy and aggregate financial market). Such phenomenon, discussed in Bikhchandani \& Sharma (2001), is referred to as spurious herding and has subsequently been investigated in Klein (2013), Bohl et al. (2014), and Galariotis et al. (2015). Consequently, heterogeneity among market participants and information could be a key factor in determining and hence to understand herd behaviour in emerging markets. Empirical research on herding behaviour in emerging markets with a focus on the role of idiosyncratic participants with heterogeneous information, however, is still scarce.

Though the literature on herd mentality in the stock market is vast, challenges remain when it comes to revealing the existence and the causing mechanism of herding empirically. One of the challenges is to purge out the impact of spurious herding so as to isolate and identify true (intentional) herding. Since information on the macro economy and the aggregate market is commonly known to the public, convergence in investors' behaviour based on such information most likely does not necessarily involve investors reversing their decisions, and thus strictly speaking, is not herding (Bikhchandani \& Sharma, 2001). It is therefore important to factor out such fundamental-driven (spurious) herding before further exploring the possibility of intentional herding. Studies that do not make such a distinction might overestimate the existence and the intensity of herding. To address this issue, we follow the approach adopted in Galariotis et al. (2015) to separate and quantify spurious and intentional herding. More specifically, we decompose return dispersion (Cross Sectional Absolute Deviation, CSAD) into two parts by regressing it on conventional return factors (i.e., size, book-to-market, and momentum) proposed 
in Fama \& French $(1995,1996)$ and Carhart $(1997) .{ }^{1}$ Given that these return factors capture significant information on the dynamics of macro economy and aggregate financial market, the fitted value of this regression captures dispersions due to investors' reaction to changes in fundamental information which can be used to investigate fundamental-driven herding, while the residuals from this regression captures dispersions due to investors responding to nonfundamental information. ${ }^{2}$ Using this approach, Galariotis et al. (2015) document nonfundamental herding in UK and US and intentional herding in US. In this paper, we explore the possibility of implementing this method using data from an emerging country. Further discussions on this approach are presented in Section 2.

Another challenge is to build a closer link between theoretical arguments and empirical studies in order to identify the cause of herd mentality. Theoretical wisdom regarding causes of herding in the literature includes herding due to informational externalities and cascades (Banerjee, 1992; Bikhchandani et al., 1992; Welch, 1992; and Bikhchandani et al., 1998), reputation-based herding (Scharfstein \& Stein, 1990; Zwiebel, 1995; Prendergast \& Stole, 1996; and Graham, 1999; Rajan, 2006), and herding due to compensation structures (Trueman, 1994; Maug \& Naik, 1996; and Admati \& Pfleiderer, 1997). ${ }^{3}$ Whilst theoretical models on this topic are well developed, most empirical studies in the current literature nevertheless are based on purely statistical approaches usually not derived from theoretical models. This is due to the fact that detailed and reliable data that could be used to directly test these theories are scarce. Though we too do not have such rich information to isolate and test the existence of various theories directly in this paper, we make an effort to search for potential dominant causes of herding by incorporating idiosyncrasy among stock market participants in the analysis to further explore herds due to responses and interactions among idiosyncratic investors when they are exposed to

\footnotetext{
${ }^{1}$ This is in line with approaches proposed by Klein (2013) and Bohl et al. (2014), who also utilised Fama-French and macroeconomics factors in their regressions to control for fundamental (spurious) herding. In our paper, we attempt to separate and quantify these two types of herding.

${ }^{2}$ Liew \& Vassalou (2000) find that the two factors HML and SMB embody significant information regarding the growth of Gross Domestic Product (GDP) in ten international markets, and that they can be used to predict future economic growth in some countries.

${ }^{3}$ See Devenow \& Welch (1995) and more recently Bikhchandani \& Sharma (2001) and Spyrou (2013) for literature review of theoretical models.
} 
informational externalities and cascades (De Long et al., 1990a; Shleifer \& Summers, 1990; Bikhchandani et al., 1992; and Bikhchandani et al., 1998).

More specifically, instead of assuming investors are homogeneous like most of the studies in the herds towards market consensus literature, following Shleifer \& Summers (1990), we assume that both arbitrageurs and noise traders exist in the stock market. Arbitrageurs are sophisticated and fully rational investors, who are more capable of identifying stocks that on average outperform the market (positive alpha) and constructing trading strategies centring on these stocks. ${ }^{4}$ They attempt to conduct arbitrage, but such action is limited as it could be risky. ${ }^{5}$ With a finite number of arbitrageurs in the market, under these assumptions, arbitrage alone is not powerful enough to direct stock prices towards their equilibrium levels. Noise traders, on the other hand, are less sophisticated investors who are not fully rational and tend to pick and trade stocks based on sentiments, and thus their trading patterns could be subject to systematic biases. ${ }^{6}$ Many trading strategies conducted by noise traders are based on pseudo-signals and are correlated to each other, leading to the same judgement biases and persistent mistakes (Shleifer $\&$ Summers, 1990). Consequently, they are more likely to hold and trade stocks that on average underperform the market (negative alpha).

Under these assumptions, in the presence of informational externalities and cascades, herds not only could happen among investors within each of these two groups (within-group herding) but

\footnotetext{
${ }^{4}$ In this paper, for each stock, we assume that the estimated Jensen's alpha (Jensen, 1968), i.e., the estimated constant obtained from an equilibrium four-factor asset pricing model based on Carhart (1997), is a sufficient indicator of expected average return over the one predicted for the underlying stock. Note that we do not assume that arbitrageurs only trade stocks with positive alphas or noise traders only trade negative alpha stocks (which is unlikely the situate in the practice), only that they are more likely to trade corresponding positive / negative alpha stocks. Due to data constraints, we are unable to further identify whether a stock is held by arbitrageurs or noise trader. However, we believe this is not an unreasonable assumption to make, and can help shed lights on the behaviour of different groups of investors in the markets.

${ }^{5}$ Shleifer \& Summers (1990) identify two sources of risks that limit arbitrage, namely fundamental risk and risk due to unpredictability of the future resale price as suggested in (De Long et al., 1990a).

${ }^{6}$ We thank an anonymous referee for pointing out that some noise traders could also be 'liquidity traders' as claimed in the literature. In this paper, we follow the definition of noise traders in Black (1986), seeing them as those "trading on noise as if it were information". This view is also adopted by De Long et al. (1990b), who note that noise traders "may get their pseudo-signals from technical analysts, stockbrokers, or economic consultants and irrationally believe that these signals carry information".
} 
also could happen due to interactions of investors between two groups (between-group herding). Within-group herding for arbitrageurs, captured by decreases in the dispersion of returns among stocks that on average outperform the market, is likely due to fund managers trading portfolios centring positive alpha stocks so as to herd to preserve reputation and/or compensation (Scharfstein \& Stein, 1990; Admati \& Pfleiderer, 1997) or due to arbitrageurs herd when they are exposed to information-based cascades. ${ }^{7}$ Bikhchandani et al. (1992) and Bikhchandani et al. (1998) show that, when the accuracy of the information with market participants is not a common knowledge, investors in the stock market, even when they are rational, may mimic the behaviour of an initial group of investors in the erroneous belief that this group knows something, leading to information cascades and herd mentality. Within-group herding for noise trader, captured by decreases in the dispersion of returns among stocks that on average underperform the market, however, is more likely due to irrational noise traders follow their intrinsic preference for conformity (Bikhchandani \& Sharma, 2001) and mimic each other's action based on sentiments or beliefs that could not be fully justified (Shleifer \& Summers, 1990). Betweengroup herding or interaction could arise when arbitrageurs make active attempts to take advantage of noise traders' moves. Given that arbitrage is risky and thus limited, arbitrageurs may as well create more positive signals if noise traders are already optimistic about particular securities so as to benefit from such herds (Shleifer \& Summers, 1990). This would trigger further market jitters and herd mentality if irrational noise traders follow positive-feedback strategies, i.e., buy when prices rise and sell when prices fall (De Long et al., 1990a). In such a situation, between-group herding or interactions among investors from these two groups arise and the measure of return dispersion for each group could be potential explanatory variable to explain the dynamics of their counterpart.

We test the above conjectures using data from Vietnam, where the stock market has been growing rapidly since 2000. We believe that Vietnam is suitable for our study for two reasons. Regarding legal regulations and market participants, as a young emerging market, Vietnam has

\footnotetext{
${ }^{7}$ Scharfstein \& Stein (1990) illustrate that, if the market does not have perfect information about fund managers' ability and there is a need to share the blame when things go bad, reputation concerns could lead managers to follow each other's actions. Maug \& Naik (1996) and Admati \& Pfleiderer (1997) both show that, in a principleagent setup and when managers' compensation depends on how their performance compares with a benchmark in the market, managers' action could be distorted and they turn to mimic each other. This usually ends up with an inefficient portfolio.
} 
relatively few rules concerning information disclosures imposed on listed firms, while at the same time noise traders are likely to exist. Truong et al. (2007) document a limited supply of reliable information on firms and trading activities in Vietnam stock market where many traders usually trade on rumours and chase trends. These features make Vietnam a suitable example for studying herds due to diverse responses and interactions among idiosyncratic investors when they are exposed to heterogeneous information. There is evidence in the literature showing that foreign investors and institutional investors are more likely to be agents of bubbles instead of domestic individual investors (Choi et al., 2015). This is less likely to be the case in Vietnam given the limited participation of foreign and institutional investors in the stock market. ${ }^{8}$ The empirical results from aggregate Vietnam market data hence can be deemed as highly representative of individual investors, which could help overcome potential bias in our study as our data is not detailed enough to identify foreign and institutional investors. The empirical results documented in this paper thus not only unveil insights into the market in Vietnam, but also contribute to our understanding of herd behaviour in general and especially for young emerging markets.

Our empirical results reveal overwhelming evidence of herd behaviour in Vietnam. Herding appears stronger on up vis-à-vis down market days, and is robust to daily price limit tests. We are also able to document evidence of a major reduction in the magnitude of herding following the recent global financial crisis. We further contribute to existing literature by modifying tests for fundamental and non-fundamental herding suggested in Galariotis et al. (2015). We note that the dispersion measure of returns among stocks, by mathematical construction, is more

\footnotetext{
${ }^{8}$ Truong et al. (2007) report that "almost $90 \%$ of trading" in the Vietnam market is done by individuals. Additionally, in a World Federation of Exchange (WFE) interview, Tran Dac Sinh, CEO of the HOSE, reveals that of more than 1.3 million trading accounts on the Ho Chi Minh Stock Exchange (HOSE), more than 98\% (1.28 million) belong to domestic individual investors. In fact, participation by foreign and institutional investors is limited in Vietnam. The exchanges in Vietnam are dominated by local individual investors. Jalil Rasheed, the investment director for Southeast Asia at Invesco, commented in Shaffer (2014) that "Vietnam at this point in time is still very much a private equity market. It's still not ready for institutional investors". Furthermore, there was a disincentive for foreign (and potentially more sophisticated) investors to participate in the Vietnam market. This discouragement stems from a cap on public joint stock company ownership by foreigners, which at first was set at $20 \%$. The limit subsequently was raised to $30 \%$ in July 2003 , and $49 \%$ in June 2009 . Decision 55/2009/QD-TTg issued by the Prime Minister of Vietnam, which comes into effect on June 1, 2009, imposed a cap of $49 \%$ on the total number of stocks of a public joint-stock company that foreign investors, as a whole, are allowed to hold. This was not relaxed until 2015, when the Prime Minister approved of Decree 60/2015/ND-CP, which essentially permits unlimited foreign ownership of public companies in Vietnam under certain circumstances. The decision does not come into effect until September 1, 2015.
} 
responsive to changes in the magnitude of fundamental factors rather than their values, and therefore replace such factors with their absolute values in the equation used for decomposing total CSAD for subsequent testing. This improves the model performance and accuracy during the process of isolating the fundamentals-driven (or "spurious") herding and non-fundamental driven (intentional) herding in the market. Another contribution is our identification strategy of potential systematic differences in the trading pattern of arbitrageurs and noise traders, assuming that a stock's abnormal return (alpha) serves as a good proxy for classifying stocks into the typical portfolios that are more likely traded by each group of investors. We document potential evidence that, aside from within-group interactions, there exist interactions between arbitrageurs and noise traders, possibly stemming from the former taking advantage of the latter's irrational trading mentality.

The remaining of this paper is outlined as follows. Section 2 describes the methodology and data used for testing of herd behaviour in the Vietnam stock market. Section 3 presents the empirical results and finally section 4 summarises the findings and discusses their implications.

\section{Data and Methodology}

\subsection{Data}

Vietnam currently has two stock exchange centres, both of which are less than two decades of age. The Ho Chi Minh Stock Exchange (HOSE) went into operation on July $20^{\text {th }} 2000$ and commenced trading on July $28^{\text {th }}$ 2000. The Hanoi Stock Exchange (HNX), on the other hand, was launched in March 2005, but did not commence trading until July 2005. In this paper, following previous literature on Vietnam stock market, we focus on the HOSE only. Although both of the two exchanges have considerable numbers of listed companies (as shown in Figure 1), the HOSE is the main exchange in Vietnam. Not only does it have a longer history, its market capitalisation has consistently been higher than the HNX, which is clearly illustrated in Figure 2. As of 19 May 2015, the total market value of all shares listed on the HOSE was over 992 trillion Vietnam Dong (45 billion US Dollars). This was more than 7 times the figure for the HNX, which stood at only 141 trillion Vietnam Dong (6.5 billion US Dollars) at the end of the same 
day. The stock market index for the HOSE is also commonly referred to as the Vietnam (VN) Index. The data employed in this paper are daily stock prices of all companies listed on the HOSE and the stock market index (VN Index) from January 2007 to May 2015, which are provided by Thomson Reuters Datastream. All prices and indices employed are adjusted closing prices and indices.

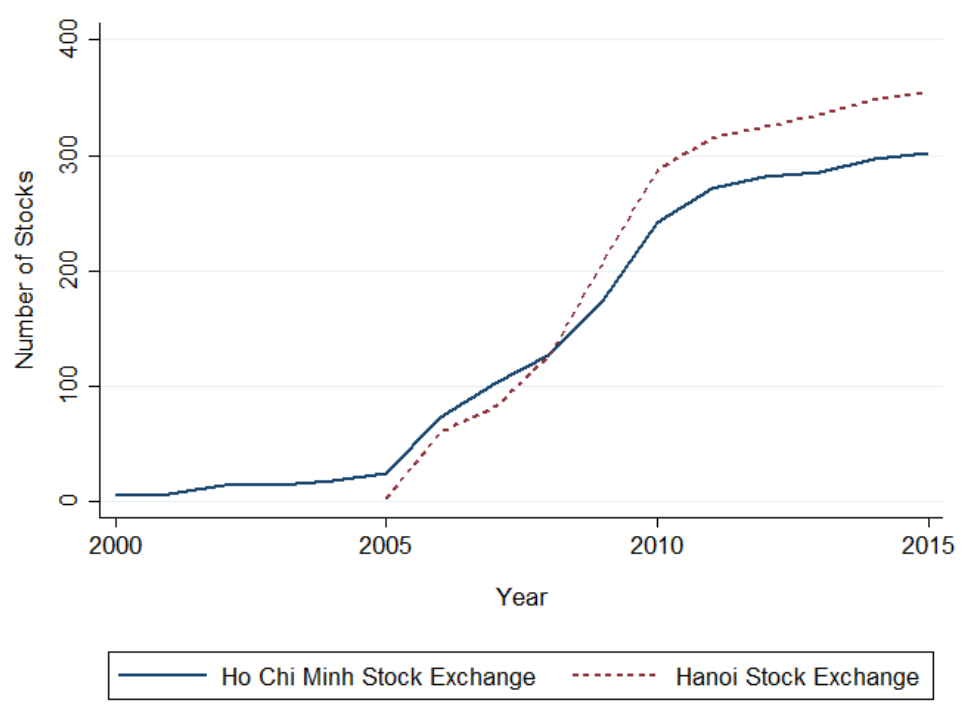

Figure 1. Number of Listed Stocks on the Ho Chi Minh and Hanoi Stock Exchanges 2000-2015.

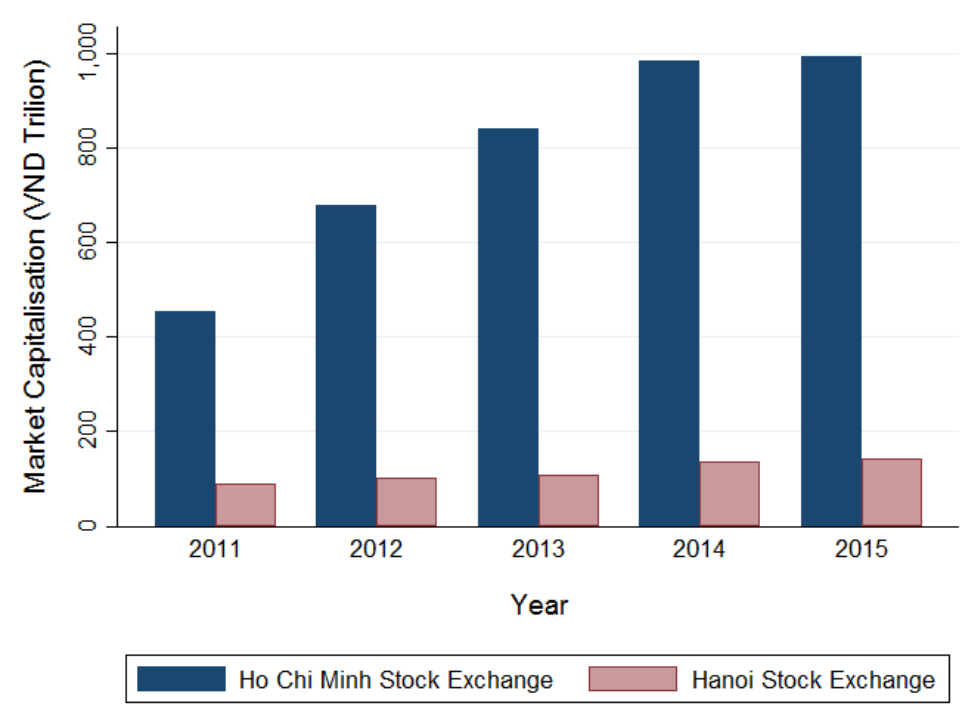

Figure 2. Market Capitalisation - Ho Chi Minh and Hanoi Stock Exchanges 2011-2015.

Figure 3 shows the movements of the HOSE index (VN Index) from its commencement in July 2000 to May 2015. The index began at 100 on 28 July 2000 and within one year grew by an 
impressive $470 \%$ to 571.04 on June 2001 . However, as this is largely attributable to a temporary surge in demand for stocks by new investors, the index dropped to around 180 by mid-2002. The market did not really begin to rally until the middle of 2005 , when the government relaxed the limit on ownership of listed companies by foreign investors from $30 \%$ to $49 \%$. A period of considerable growth lasted from then until early 2007, around the time the Law on Securities came into effect (1 January) and Vietnam officially became a member of the World Trade Organisation (WTO) (11 January). This culminated in an all-time high of the index of 1,170.67 on 12 March 2007. The market did not stay at that level for long. After peaking, fuelled by the global financial crisis, the index began a downward trend, which did not end until 24 February 2009 , when it hit a 4-year low of 235.50. Since then, the market has been gradually recovering and the index stood at 536.82 at the last day of observation (19 May 2015) in our dataset.

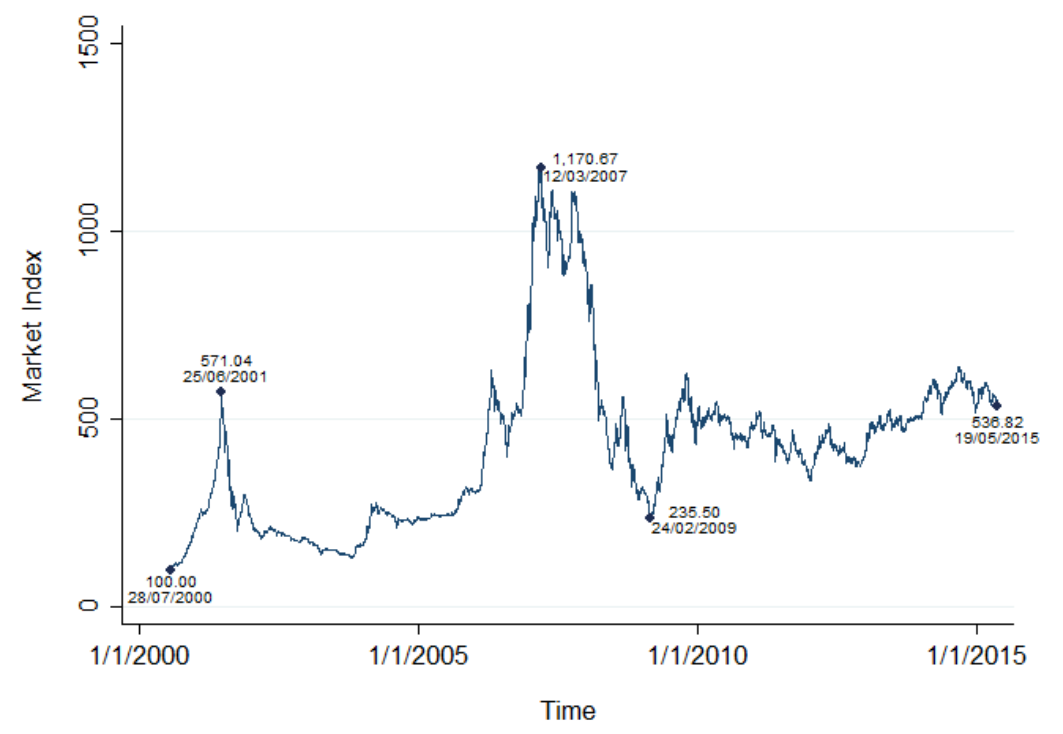

Figure 3. Vietnam Stock Market Index - July 2000 to May 2015.

Data source: Thompson Reuters Datastream.

\subsection{Measures of Dispersion and Benchmark Specifications}

This section reviews measures of dispersion and model specifications commonly adopted in the literature, which forms the starting point of our empirical investigation. The literature on testing for herding towards market consensus largely follows Christie \& Huang (1995), Chang et al. (2000), and Chiang \& Zheng (2010). The two measures of dispersion commonly used are cross- 
sectional standard deviation (CSSD) and cross-sectional absolute deviation (CSAD) of returns, which are defined as follows:

$$
\begin{gathered}
\operatorname{CSSD}_{t}=\sqrt{\frac{1}{N-1} \sum_{i=1}^{N}\left(R_{i, t}-R_{m, t}\right)^{2}} \\
C S A D_{t}=\frac{1}{N} \sum_{i=1}^{N}\left|R_{i, t}-R_{m, t}\right|
\end{gathered}
$$

where $R_{i, t}$ is the actual stock return of firm $i$ at time $t$, and $R_{m, t}$ is the actual cross-sectional average of all the $N$ stock returns in the market portfolio at time $t$. Both measures quantify the average deviation of individual stock returns from the market return $\left(R_{i, t}-R_{m, t}\right)$. To avoid positive and negative deviations cancelling out, CSSD takes the square root of the average squared deviations, while CSAD simply averages out the absolute values of the deviations. $C S S D_{t}$ and $C S A D_{t}$ will both increase when individual stock returns deviate from the market return. Decreases in the value of either dispersion measure would suggest that return on the market and stock returns are close together and hence could be a signal of potential herds towards market consensus.

Different stocks have different degrees of sensitivity to the market, which will cause the dispersion to increase as the market return increases in absolute term. The presence of herd mentality during the extreme market movements, however, will draw individual returns closer to the market return, thus reducing dispersion. Christie \& Huang (1995) hence propose the following dummy variable regression to test for herd behaviour:

$$
\operatorname{CSSD}_{t}=\alpha+\beta_{L} D_{t}^{L}+\beta_{U} D_{t}^{U}+\varepsilon_{t}
$$

where $D_{t}^{L}$ and $D_{t}^{U}$ are dummy variables which equal 1 when the market return on day $t$ lies in the extreme lower and upper tail, respectively, of the distribution, and are equal to 0 otherwise; $\varepsilon_{t}$ is a random error term. Two criteria, $1 \%$ and $5 \%$ of the lower and upper tails of the market return distribution, are commonly set for extreme market movements. Under this specification, negative and statistically significant estimates of $\beta_{L}$ and $\beta_{U}$ would indicate herd behaviour in the market. The same logic applies when dependent variable is replaced by $C S A D_{t}$. 
Chang et al. (2000) illustrate that herding, if it exists, would introduce a non-linear relationship between $C S A D_{t}$ and $R_{m, t}$, leading to disproportional changes in the $C S A D_{t}$ when investors follow aggregate market behaviour during periods of large average price movements. Chang et al. (2000) hence propose the following regression, which expresses $C S A D_{t}$ as a quadratic function of $R_{m, t}$ :

$$
\operatorname{CSAD}_{t}=\gamma_{0}+\gamma_{1}\left|R_{m, t}\right|+\gamma_{2} R_{m, t}^{2}+\varepsilon_{t}
$$

The absolute term $\left|R_{m, t}\right|$ is included to capture the predicted linear relationship between return dispersion and mean return, while the quadratic term $R_{m, t}^{2}$ serves to capture possible nonlinearity in the relationship. If the market exhibits herd behaviour, return dispersion will either increase at a less-than-proportional rate, or in extreme cases, decrease with the market return, resulting in a negative and significant estimate $\left(\gamma_{2}\right)$ for the quadratic term. Note that equation (4) does not require the market to be at the extreme to pick up signs of herd mentality. Chang et al. (2000) illustrate that in the case of herd behaviour in an up market, equation (4) becomes $\operatorname{CSAD}_{t}=\alpha+\gamma_{1} R_{m, t}+\gamma_{2} R_{m, t}^{2}+\varepsilon_{t}$ with a negative $\gamma_{2}$ coefficient, suggesting that $\operatorname{CSAD}_{t}$ does not start trending down until $R_{m, t}$ reaches the value of $R_{m, t}^{*}=-\frac{\gamma_{1}}{2 \gamma_{2}}$. Thus, the dummy variable regression proposed in Christie \& Huang (1995) may fail to yield negative signs of $\beta_{U}$ if the $95^{\text {th }}$ or $99^{\text {th }}$ percentile of $R_{m, t}$ is below $R_{m, t}^{*}$. While it is still possible for this specification to detect herding, it nevertheless requires a far greater magnitude of non-linearity in the return dispersion and mean return relationship for evidence of herding to surface.

Chiang \& Zheng (2010) introduce additional regressors to increase the models' explanatory power, as well as to incorporate the interactions between stock markets in different countries. Specifically, the first major modification is the inclusion of $R_{m, t}$ as a regressor:

$$
\operatorname{CSAD}_{t}=\gamma_{0}+\gamma_{1} R_{m, t}+\gamma_{2}\left|R_{m, t}\right|+\gamma_{3} R_{m, t}^{2}+\varepsilon_{t}
$$

This modification has a benefit of capturing any potential asymmetry in the relationship between market return and dispersion under different market conditions (up and down). In particular, for every unit change in market return, $C S A D_{t}$ changes by $\gamma_{2}+\gamma_{1}$ for positive $R_{m, t}$ and by $\gamma_{2}-\gamma_{1}$ negative $R_{m, t}$. Asymmetry between dispersion and market return would be quantified by the ratio 
$\frac{\gamma_{2}+\gamma_{1}}{\gamma_{2}-\gamma_{1}}$. As a second way to test for differences in investor reactions on days when the market is up as opposed to when the market is down, Chiang \& Zheng (2010) further propose to segregate the data into two groups by replacing $R_{m, t}$ with $(1-D) R_{m, t}$ and $D R_{m, t}$, and $R_{m, t}^{2}$ with $(1-D) R_{m, t}^{2}$ and $D R_{m, t}^{2}$, where $D$ is a dummy variable that equals 1 when $R_{m, t}<0$ and 0 otherwise. Following this specification, Chiang \& Zheng (2010) document that herding is more apparent in Asian markets during up periods, and asymmetry does not exist in the advanced markets.

The increasing integration of financial markets around the world and the leading role of the US market in international financial transactions have motivated researchers to further modify the specification as:

$$
C S A D_{t}=\gamma_{0}+\gamma_{1} R_{m, t}+\gamma_{2}\left|R_{m, t}\right|+\gamma_{3} R_{m, t}^{2}+\gamma_{4} C S A D_{U S, t}+\gamma_{5} R_{U S, m, t}^{2}+\varepsilon_{t}
$$

where $C S A D_{U S, t}$ and $R_{U S, m, t}^{2}$ respectively represent the cross-sectional standard deviation and aggregate return for the US market. There is evidence in the literature showing that the two additional regressors improve the models' explanatory power, indicated by higher adjusted Rsquared values. The coefficients on $C S A D_{U S, t}\left(\gamma_{4}\right)$ are significantly positive in some studies (Chiang \& Zheng, 2010; Hwang et al., 2013; Galariotis et al., 2015), suggesting a potential cross-country influence of the US return dispersions in international markets, which Chiang \& Zheng (2010) interpret as a signal of shock transmissions between similar sectors across national borders. This reveals that while some markets might not herd among themselves, they herd with the US market.

\subsection{Separating Dispersion due to Fundamental and Non-fundamental Information}

Following Galariotis et al. (2015), we decompose the total $C S A D_{t}$ into two components, one to capture reactions to fundamental factors, and the other to capture reactions to non-fundamental factors. ${ }^{9}$ This is achieved by estimating the following equation:

$$
C S A D_{t}=\beta_{0}+\beta_{1}\left(R_{m, t}-R_{f}\right)+\beta_{2} S M B_{t}+\beta_{3} H M L_{t}+\beta_{4} M O M_{t}+\varepsilon_{t}
$$

\footnotetext{
${ }^{9}$ Given that $C S S D_{t}$ is sensitive to outliners as suggested in the literature, we focus on $C S A D_{t}$ for this part of analysis. We however obtain similar results using $C S S D_{t}$ measure. These results are available upon request.
} 
The fitted values of $C S A D_{t}$ from equation (7) are defined as deviations due to fundamentals $\left(C S A D_{F U N D, t}\right)$, while the residuals are defined as deviations due to non-fundamentals $\left(C S A D_{N O N F U N D, t}\right)$. Following Chiang \& Zheng (2010) these variables are then used as dependent variables for the following models:

$$
\begin{gathered}
\operatorname{CSAD}_{F U N D, t}=\gamma_{0}+\gamma_{1} D R_{m, t}+\gamma_{2}(1-D) R_{m, t}+\gamma_{3} D R_{m, t}^{2}+\gamma_{4}(1-D) R_{m, t}^{2}+\varepsilon_{t} \\
\operatorname{CSAD}_{\text {NONFUND }, t}=\gamma_{0}+\gamma_{1} D R_{m, t}+\gamma_{2}(1-D) R_{m, t}+\gamma_{3} D R_{m, t}^{2}+\gamma_{4}(1-D) R_{m, t}^{2}+\varepsilon_{t}
\end{gathered}
$$

Equation (8) is used to test for and quantify spurious herding, whilst (9) is employed to detect and quantify intentional herding. The dummy variable $D$ (equals 1 when $R_{m, t}>0$ and 0 otherwise) is employed to identify potential difference in investors' behaviour in the up $\left(\gamma_{3}\right)$ market and down $\left(\gamma_{4}\right)$ market.

\subsection{Measures for Within-group Herding and Between-group Herding}

To identify potential within- and between-group herding, following previous discussion, we segment stocks into two groups according to their alpha values and calculate $C S A D_{t}$ for each of these two groups. More specifically, we obtained estimated alpha value for each stock by firstly regressing the returns of each stock against factors in a four-factor model as proposed by Carhart (1997). The alpha values are recalculated on a yearly basis. Two $\operatorname{CSAD}_{t}$ measures are then calculated: one based on stocks with positive alphas $\left(C S A D_{+, t}\right)$, and the other one based on stocks with negative alphas $\left(C S A D_{-, t}\right)$. These two dispersion measures are then entered into the following regressions:

$$
\begin{gathered}
C S A D_{+, t}=\gamma_{0}+\gamma_{1} R_{+m, t}+\gamma_{2}\left|R_{+m, t}\right|+\gamma_{3} R_{+m, t}^{2}+\gamma_{4} R_{-m, t}^{2}+\gamma_{5} \operatorname{CSAD}_{-, t}+\varepsilon_{t} \\
C S A D_{-, t}=\gamma_{6}+\gamma_{7} R_{-m, t}+\gamma_{8}\left|R_{-m, t}\right|+\gamma_{9} R_{-m, t}^{2}+\gamma_{10} R_{+m, t}^{2}+\gamma_{11} C S A D_{+, t}+\varepsilon_{t}
\end{gathered}
$$

where $R_{+m, t}^{2}$ and $R_{-m, t}^{2}$ are equally weighted (sub)market returns using stocks falling into positive and negative alpha group, respectively. Negative and significant estimates for $\gamma_{3}$ and $\gamma_{9}$ would indicate within-group herding, while negative and significant estimates for $\gamma_{4}$ and $\gamma_{10}$ would signal between-group herding. Significant estimates for $\gamma_{5}$ and $\gamma_{11}$ would indicate interactions among investors from these two groups. 
Empirical results based on benchmark measures and specifications reviewed above are presented in the next section. To compare our results with those reported in the literature, we first present and discuss results that do not distinguish fundamental and non-fundamental herding. Results making such distinction, as well as evidence on within- and between-group herding, will be discussed subsequently.

Table 1 provides summary statistics of $R_{m, t}, \operatorname{CSSD}_{t}$ and $C S A D_{t}$ for the HOSE under two proxies for the market return (Panel A: returns on an equally weighted portfolio constructed from data and Panel B: returns on the VN Index, i.e., capitalization-weighted index reported by Datastream). After the data cleaning process, which is reported in Appendix A, 2051 observations remained. Since the observations start when the index was near its peak in March 2007 and end before the market had the chance to fully recover from the global financial crisis, the mean of $R_{m, t}$ under both definitions are negative, and the lower mean for Panel A $(-0.060 \%)$ compared to Panel B $(-0.032 \%)$ suggests that small stocks yielded lower returns than large stocks during the sample period. In both panels, the mean, standard deviation and maximum of $\operatorname{CSSD}_{t}$ are all higher than $\operatorname{CSAD}_{t}$. This is in line with the remark in Chiang \& Zheng (2010) on the sensitivity of $C S S D_{t}$ to outliers. In addition, values in Panel A are lower than their Panel B counterpart, which follows the fact that the unweighted average (or equally weighted) minimizes the sum of squared deviations.

The major time series variables appear to be stationary as suggested by augmented Dickey-Fuller test statistics (Dickey \& Fuller, 1979), all of which are significant at the 1\% level. However, they also appear to be serially correlated, having significant first-order lag coefficients ranging from 0.253 to 0.335 . Therefore, all subsequent testing is done using heteroscedasticity and autocorrelation consistent (HAC) standard errors developed by Newey \& West (1987). The reported standard errors in this paper were estimated using a lag length of 6 for HAC standard errors, as $\operatorname{CSSD}_{t}$ and $C S A D_{t}$ do not exhibit statistically significant autocorrelation of order 7 or above. The significance of the coefficients and conclusions would remain unchanged if we increased the lag length to 10 , following the conventional truncation parameter guideline suggested in Stock \& Watson (2011). 


\section{Table 1}

Summary Statistics of $R_{m, t}, C S S D_{t}$ and $C S A D_{t}$ for the HOSE.

\begin{tabular}{|c|c|c|c|c|c|c|c|c|c|c|}
\hline \multirow{2}{*}{$\begin{array}{c}\text { Mean } \\
(\%)\end{array}$} & \multirow{2}{*}{$\begin{array}{c}\text { Standard } \\
\text { Deviation } \\
(\%)\end{array}$} & \multirow{2}{*}{$\begin{array}{c}\text { Minimum } \\
\text { (\%) }\end{array}$} & \multirow{2}{*}{$\begin{array}{c}\text { Maximum } \\
(\%)\end{array}$} & \multicolumn{7}{|c|}{ Serial Correlation at Lags } \\
\hline & & & & 1 & 2 & 3 & 4 & 5 & 6 & $\begin{array}{c}\text { ADF } \\
\text { Statistic }\end{array}$ \\
\hline
\end{tabular}

Panel A: Measures computed using returns on an equally weighted portfolio

\begin{tabular}{ccccccccccccc}
$R_{m, t}$ & -0.060 & 1.524 & -4.839 & 4.770 & $0.315^{* * *}$ & $-0.058^{* *}$ & $0.057^{* *}$ & $0.082^{* * *}$ & 0.029 & -0.014 & $-14.569^{* * *}$ \\
$C S S D_{t}$ & 2.423 & 0.523 & 0.000 & 4.585 & $0.335^{* * *}$ & $0.099^{* * *}$ & $0.131^{* * *}$ & $0.045^{*}$ & $0.133^{* * *}$ & $0.089^{* * *}$ & $-7.409^{* * *}$ \\
$C S A D_{t}$ & 1.839 & 0.482 & 0.129 & 3.979 & $0.315^{* * *}$ & $0.101^{* * *}$ & $0.095^{* * *}$ & $0.056^{* *}$ & $0.119^{* * *}$ & $0.079^{* * *}$ & $-8.710^{* * *}$ \\
\hline
\end{tabular}

Panel B: Measures computed using returns on the stock market index (VN Index)

\begin{tabular}{ccccccccccccc}
$R_{m, t}$ & -0.032 & 1.579 & -6.051 & 4.647 & $0.253^{* * *}$ & $-0.041^{*}$ & 0.023 & $0.071^{* * *}$ & 0.013 & -0.013 & $-15.417^{* * *}$ \\
$C S S D_{t}$ & 2.509 & 0.569 & 0.000 & 5.663 & $0.318^{* * *}$ & $0.099^{* * *}$ & $0.131^{* * *}$ & $0.055^{* *}$ & $0.120^{* * *}$ & $0.094^{* * *}$ & $-7.927^{* * *}$ \\
$C S A D_{t}$ & 1.912 & 0.515 & 0.130 & 4.899 & $0.303^{* * *}$ & $0.097^{* * *}$ & $0.108^{* * *}$ & $0.046^{* *}$ & $0.119^{* * *}$ & $0.088^{* * *}$ & $-8.821^{* * *}$ \\
\hline
\end{tabular}

Notes:

a) This table presents the daily mean, standard deviation, minimum and maximum values of returns $\left(R_{m, t}\right)$, cross-sectional standard deviation $\left(C S S D_{t}\right)$ and crosssectional absolute deviation $\left(C S A D_{t}\right)$ for the Ho Chi Minh Stock Exchange (HOSE) in Vietnam.

b) The deviations series are computed using equations (1) and (2)

c) The sample range is from 31 January 2007 to 19 May 2015. Serial correlation is reported for lags 1 to 6, along with test statistics of the Augmented DickeyFuller (ADF) test.

d) ${ }^{*},{ }^{* *}$ and ${ }^{* * *}$ indicate statistical significance at the $10 \%, 5 \%$ and $1 \%$ respectively. 


\section{Empirical Results and Discussion}

\subsection{Dummy Variable Regression}

Table 2 reports the estimation results based on equation (3) proposed by Christie \& Huang (1995). We also present in Table 2 the threshold $\left(L_{m}\right)$ which $R_{m, t}$ has to fall below for to be considered to lie in the lower tail of the distribution, as well as the threshold $\left(U_{m}\right)$ which $R_{m, t}$ has to rise above to be considered to lie in the upper tail of the distribution. These thresholds are affected by the criteria of $1 \%, 2 \%$ and $5 \%$ shown in the first column.

Since we do not distinguish fundamental herding and intentional herding at this stage, the results potentially capture the effect of both of these two. Firstly, the table provides clear and overwhelming evidence of herd behaviour, as all estimates of $\beta_{L}$ and $\beta_{U}$ are negative and statistically significant even at the $1 \%$ level. The results are robust to different definitions of $R_{m, t}$ and different measures of return dispersion $\left(C S A D_{t}\right.$ and $\left.C S S D_{t}\right)$.

Secondly, the degree of herding appears to increase with the extremeness of the market. As the percentage of observations of market returns classified as extreme decreases (from 5\% to $1 \%$ percentile), the estimated dummy variable coefficients become more negative. For instance, in Panel A1, the estimates for $\beta_{U}$ decrease from -0.584 to -0.987 and to -1.438 as the criterion changes from $5 \%$ to $2 \%$ and $1 \%$, respectively. Likewise, in Panel B2, $\beta_{L}$ coefficient decreases from -0.356 ( $5 \%$ percentile) to -1.067 ( $1 \%$ percentile) ${ }^{10}$

Thirdly, in terms for asymmetry in herd behaviour, in all models, the $\beta_{U}$ coefficients are all more negative than their $\beta_{L}$ counterparts. However, the null hypothesis that $\beta_{U}=\beta_{L}$ is rejected in some cases. This provides partial evidence of asymmetry of herd behaviour between up and down markets. Nevertheless, these results only describe herding during market stress periods, and thus cannot be generalised to the normal day-to-day behaviour of participants. As such, we now turn to empirical tests that are less stringent and do not require defining extreme market movements.

\footnotetext{
${ }^{10}$ Note that a similar pattern can be seen in Chang et al. (2000) for the stocks in Taiwan on up market days.
} 
Table 2

Dummy Variable Regression.

\begin{tabular}{lllllllll}
\hline Criteria & Constant & $\beta_{L}$ & $\beta_{U}$ & $L_{m}(\%)$ & $U_{m}(\%)$ & $\overline{R^{2}}$ & $\chi^{\mathbf{2}}$ & $p$-value \\
\hline
\end{tabular}

Panel A1: CSSD regression results using return on an equally weighted portfolio

$\begin{array}{llccccccc}1 \% & 2.449^{* * *} & -0.973^{* * *} & -1.438^{* * *} & -4.280 & 3.999 & 0.117 & 9.956^{* * *} & 0.002 \\ & {[0.024]} & {[0.102]} & {[0.107]} & & & & & \\ 2 \% & 2.459^{* * *} & -0.735^{* * *} & -0.987^{* * *} & -3.889 & 3.404 & 0.111 & 3.073^{*} & 0.080 \\ & {[0.024]} & {[0.096]} & {[0.108]} & & & & & \\ 5 \% & 2.472^{* * *} & -0.387^{* * *} & -0.584^{* * *} & -2.810 & 2.497 & 0.081 & 5.556^{* *} & 0.019 \\ & {[0.025]} & {[0.060]} & {[0.072]} & & & & & \\ \end{array}$

Panel A2: CSAD regression results using return on an equally weighted portfolio

$\begin{array}{llccccccc}1 \% & 1.863^{* * *} & -1.067^{* * *} & -1.292^{* * *} & -4.280 & 3.999 & 0.121 & 3.423^{*} & 0.064 \\ & {[0.020]} & {[0.102]} & {[0.066]^{* * *}} & & & & & \\ 2 \% & 1.874^{* * *} & -0.825^{* * *} & -0.906^{* * *} & -3.889 & 3.404 & 0.126 & 0.473 & 0.492 \\ & {[0.021]} & {[0.093]} & {[0.080]} & & & & & \\ 5 \% & 1.879^{* * *} & -0.356^{* * *} & -0.442^{* * *} & -2.810 & 2.497 & 0.062 & 1.181 & 0.277 \\ & {[0.022]} & {[0.063]} & {[0.066]} & & & & & \end{array}$

Panel B1: CSSD regression results using return on the market index (VN index)

$\begin{array}{llccccccc}1 \% & 2.531^{* * *} & -0.680^{* * *} & -1.299^{* * *} & -4.337 & 3.957 & 0.071 & 5.538^{* *} & 0.019 \\ & {[0.025]} & {[0.194]} & {[0.197]} & & & & & \\ 2 \% & 2.538^{* * *} & -0.534^{* * *} & -0.858^{* * *} & -3.923 & 3.522 & 0.063 & 2.774^{*} & 0.096 \\ & {[0.025]} & {[0.142]} & {[0.141]} & & & & & \\ 5 \% & 2.538^{* * *} & -0.221^{* * *} & -0.358^{* * *} & -2.874 & 2.572 & 0.024 & 1.491 & 0.222 \\ & {[0.026]} & {[0.085]} & {[0.091]} & & & & & \\ \end{array}$

Panel B2: CSAD regression results using return on the market index (VN index)

$\begin{array}{lllllllll}1 \% & 1.934^{* * *} & -0.909^{* * *} & -1.194^{* * *} & -4.337 & 3.957 & 0.084 & 1.934 & 0.164 \\ & {[0.022]} & {[0.161]} & {[0.142]} & & & & & \\ 2 \% & 1.943^{* * *} & -0.703^{* * *} & -0.819^{* * *} & -3.923 & 3.522 & 0.085 & 0.604 & 0.437 \\ & {[0.022]} & {[0.118]} & {[0.106]} & & & & & \\ 5 \% & 1.941^{* * * *} & -0.275^{* * *} & -0.304^{* * *} & -2.874 & 2.572 & 0.028 & 0.090 & 0.765 \\ & {[0.023]} & {[0.077]} & {[0.078]} & & & & & \end{array}$

Notes:

a) This table reports estimated coefficients of the following regression model: $Y_{t}=\alpha+\beta_{L} D_{t}^{L}+\beta_{U} D_{t}^{U}+\varepsilon_{t}$, where $Y_{t}$ is $\operatorname{CSAD}_{t}$ or $\operatorname{CSSD}_{t} ; D_{t}^{L}\left(D_{t}^{U}\right)$ equals 1 if the market return on day $t$ lies in the extreme lower (upper) tail of the distribution. The $1 \%, 2 \%$ and $5 \%$ criteria refer to the percentage of observations in the upper and lower tail of the market return distribution. $\chi^{2}$ and $p$-value are statistics for the Wald test with the null hypothesis $H_{0}: \beta_{U}=\beta_{L}$.

b) Newey-West HAC standard errors are reported in square brackets.

c) Column $L_{m}$ shows the $1^{\text {st }}, 2^{\text {nd }}$ and $5^{\text {th }}$ percentiles of $R_{m}$. $D_{t}^{L}$ is given the value of 1 for all observations with values $R_{m}$ lower than $L_{m}$. Column $U_{m}$ shows the $95^{\text {th }}, 98^{\text {th }}$ and $99^{\text {th }}$ percentiles of $R_{m} . D_{t}^{U}$ is given the value of 1 for all observations with values $R_{m}$ higher than $L_{m}$.

d) Panels A1 and A2 report results using the return on an equally weighted portfolio as a proxy for the market return. Panel B1 and B2 report results using the return on the capitalization-weighted stock market index (VN index) as a proxy for the market return.

e) ${ }^{*},{ }^{* *}$ and ${ }^{* * *}$ indicate statistical significance at the $10 \%, 5 \%$ and $1 \%$ respectively. 


\subsection{Tests for Herd Behaviour using Chang et al. (2000) Specification \& Further Tests for Herding Asymmetry}

Table 3 presents the regression based on the specification proposed in Chang et al. (2000), which explores the non-linearity in the $C S A D$-market return relationship in the presence of herding. Again, the results are indicative of herd behaviour, with all estimated $\gamma_{2}$ coefficients being negative and statistically significant at the $1 \%$ level, ranging from -0.124 to -0.158 . To illustrate the effect of herd formations in the market, consider the up market model in Panel A. The fitted values of the return dispersion follow the quadratic function:

$$
\widehat{C S A D}_{t}=1.664+0.476 \times\left|R_{m, t}\right|-0.158 R_{m, t}^{2}, \forall R_{m, t}>0
$$

As the (absolute) return on the market goes up, rational market forces act to drive individual stock returns away from each other, thus raising return dispersion by $0.476 \%$ on average (the coefficient on $R_{m, t}$ ) for each percentage increase in market return. At the same time, however, there are also irrational forces (herd behaviour) at work, which draw individual returns closer together, as evidenced by the negative coefficient -0.158 on the quadratic term $R_{m, t}^{2}$. At lower levels of $R_{m, t}$, the combined effect of these forces results in $C S A D_{t}$ rising at a less-thanproportional rate with $R_{m, t}$. Once the market return reaches a certain level, in this case 1.503(\%) $=-\frac{0.476}{2 \times(-0.158)}, C S A D_{t}$ will even decrease with $R_{m, t}$ (shown in Figure 4). It is also this level that the extreme observations of $R_{m, t}$ need to exceed for the Christie \& Huang (1995) test to start picking up evidence of herding (that is, to yield negative $\beta_{U}$ estimates). As shown in the last section, the Christie \& Huang (1995) specification in this case did manage to pick this up, since even the broadest criterion (5\%) for extreme movements requires $R_{m, t}$ to be as high as $2.497 \%$ (see Table 2) in the sample. A similar analysis can be performed with the down market considered. As illustrated in Figure 5, in the case of a bear market, $C S A D_{t}$ starts narrowing once the market falls by at least 1.711(\%). 


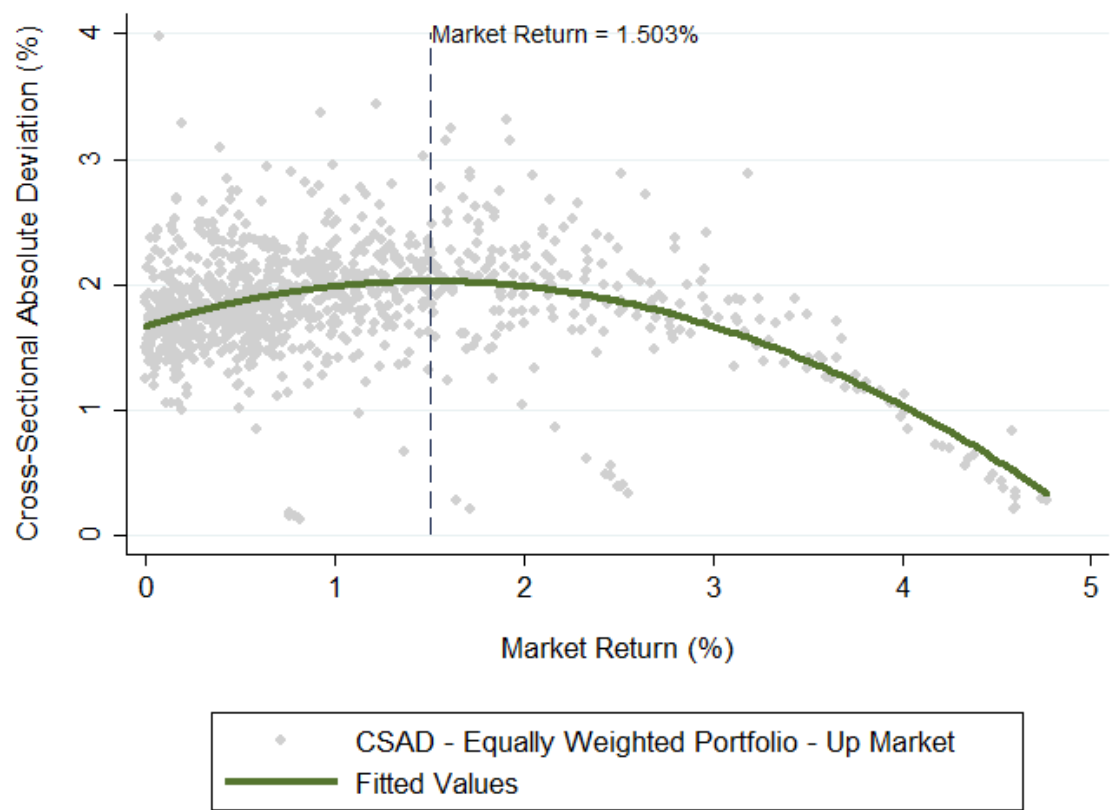

Figure 4. CSAD and Return on Equally Weighted Portfolio on Up Market Days.

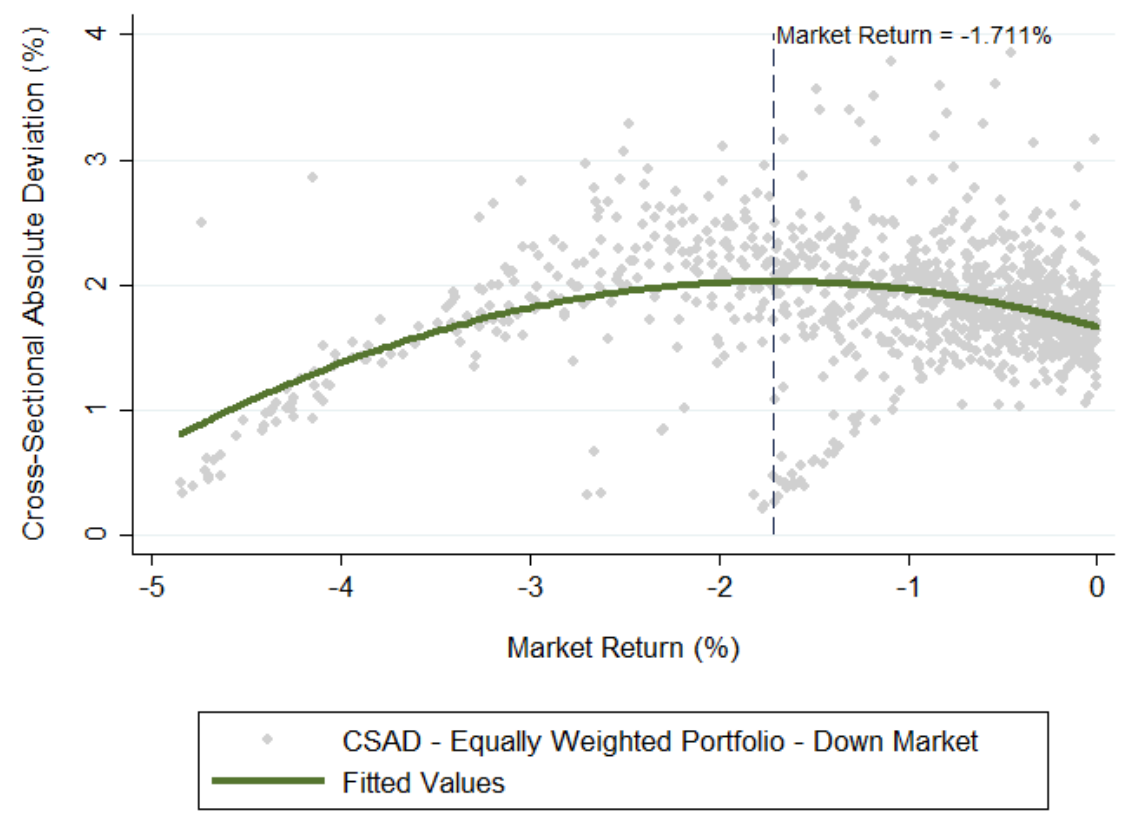

Figure 5. CSAD and Return on Equally Weighted Portfolio on Down Market Days. 


\section{Table 3}

Results based on Chang et al. (2000) Specification.

\begin{tabular}{ccccccc}
\hline $\begin{array}{c}\text { Up/Down } \\
\text { Market }\end{array}$ & $\begin{array}{c}\text { Constant } \\
\left(\gamma_{\mathbf{0}}\right)\end{array}$ & $\begin{array}{c}\left|\boldsymbol{R}_{\boldsymbol{m}, \boldsymbol{t}}\right| \\
\left(\boldsymbol{\gamma}_{\mathbf{1}}\right)\end{array}$ & $\begin{array}{c}\boldsymbol{R}_{\boldsymbol{m}, \boldsymbol{t}}^{2} \\
\left(\boldsymbol{\gamma}_{\mathbf{2}}\right)\end{array}$ & $\overline{\boldsymbol{R}^{\mathbf{2}}}$ & $\chi^{\mathbf{2}}$ & $\boldsymbol{p}$-value \\
\hline Up & $1.664^{* * * *}$ & $0.476^{* * *}$ & $-0.158^{* * *}$ & 0.226 & & \\
& {$[0.032]$} & {$[0.050]$} & {$[0.011]$} & & & \\
\multirow{2}{*}{ Down } & $1.659^{* * *}$ & $0.425^{* * *}$ & $-0.124^{* * *}$ & 0.139 & $7.183^{* * *}$ & 0.007 \\
& {$[0.032]$} & {$[0.077]$} & {$[0.019]$} & & & \\
\hline
\end{tabular}

Notes:

a) This table reports estimated coefficients of the following regression model: $\operatorname{CSAD}_{t}=\gamma_{0}+\gamma_{1}\left|R_{m, t}\right|+\gamma_{2} R_{m, t}^{2}+$ $\varepsilon_{t}$, where $\left|R_{m, t}\right|$ denotes the absolute return on the market and $R_{m, t}^{2}$ represents the squared market return. In the up/down model, all observations are restricted to those with positive/negative $R_{m, t} \cdot \chi^{2}$ and $p$-value are statistics for the Wald test with the null hypothesis $H_{0}: \gamma_{2}^{U P}=\gamma_{2}^{D O W N}$.

b) Newey-West HAC standard errors are reported in square brackets.

c) ${ }^{*},{ }^{* *}$ and ${ }^{* * *}$ indicate statistical significance at the $10 \%, 5 \%$ and $1 \%$ respectively.

To allow for asymmetry in investor behaviour during up market days and down market days, we adopt the following specifications proposed in Chiang \& Zheng (2010):

$$
C S A D_{t}=\gamma_{0}+\gamma_{1} D R_{m, t}+\gamma_{2}(1-D) R_{m, t}+\gamma_{3} D R_{m, t}^{2}+\gamma_{4}(1-D) R_{m, t}^{2}+\varepsilon_{t}
$$

where $D$ takes on the value of 1 for observations with $R_{m, t}>0$, and 0 otherwise. The coefficients on $D R_{m, t}$ and $(1-D) R_{m, t}$ reflect the relationship between $C S A D_{t}$ and $R_{m, t}$ when the market is up and down, respectively. The coefficients on $D R_{m, t}^{2}$ and $(1-D) R_{m, t}^{2}$, on the other hand, respectively capture the levels of herding in the market during up and down movements.

The results are reported in Table 4 . The herding coefficients $\left(\gamma_{3}\right.$ and $\left.\gamma_{4}\right)$, are still negative and statistically significant at the $1 \%$ level, once again confirming the robustness of herd behaviour in the Vietnam market. The coefficients for $D R_{m, t}^{2}$ (herding in the up market) are more negative than for $(1-D) R_{m, t}^{2}$ (herding in the down market). Two-sided Wald tests reject thenull hypothesis of herding symmetry $\left(H_{0}: \gamma_{3}=\gamma_{4}\right)$ in model (a) at the $5 \%$ level and in model (b) at the $10 \%$ level, while one-sided tests $\left(H_{a}: \gamma_{3}<\gamma_{4}\right)$ reject the null hypothesis in both cases at the 
5\% level. These results imply that herding is stronger in the up market vis-à-vis the down market.

Note that the above findings of stronger herd forces during the up market are consistent with previous studies on herds in Asian financial markets. Chang et al. (2000) document that for Taiwan the null hypothesis of herding symmetry is rejected at the $1 \%$ level. Chiang \& Zheng (2010) find the herding effect for a group of Asian countries to be stronger in up markets than in down markets, especially in China, Japan, and Hong Kong. It is also worth noting that all the strong evidence of herding asymmetry documented came from the models that use the returns on an equally weighted portfolio as the proxy for market returns $R_{m, t}$. Most of the Wald statistics from such models are significant at the $1 \%$ level or lower, while those from the models using the market index return (capitalisation-weighted index) as a proxy for $R_{m, t}$ are either insignificant or significant at the $10 \%$ level only. Since the equally weighted portfolios give individual returns equal weights, and the market index approach gives more weights to larger capitalisation stocks, it can be inferred that the stronger herding force documented in the up market comes from small capitalisation stocks. 


\section{Table 4}

Further Tests for Asymmetry in Herd Behaviour.

\begin{tabular}{|c|c|c|c|c|c|c|}
\hline Model & $\begin{array}{c}\text { Constant } \\
\left(\gamma_{0}\right) \\
\end{array}$ & $\begin{array}{c}D R_{m, t} \\
\left(\gamma_{1}\right)\end{array}$ & $\begin{array}{c}(1-D) R_{m, t} \\
\left(\gamma_{2}\right)\end{array}$ & $\begin{array}{c}D R_{m, t}^{2} \\
\left(\gamma_{3}\right) \\
\end{array}$ & $\begin{array}{c}(1-D) R_{m, t}^{2} \\
\left(\gamma_{4}\right)\end{array}$ & $\overline{R^{2}}$ \\
\hline \multicolumn{7}{|c|}{ Panel A: Regression Results } \\
\hline (a) & $\begin{array}{l}1.662^{* * *} \\
{[0.023]}\end{array}$ & $\begin{array}{l}0.480^{* * *} \\
{[0.043]}\end{array}$ & $\begin{array}{c}-0.422^{* * *} \\
{[0.064]}\end{array}$ & $\begin{array}{c}-0.159^{* * *} \\
{[0.010]}\end{array}$ & $\begin{array}{c}-0.124^{* * *} \\
{[0.016]}\end{array}$ & 0.179 \\
\hline (b) & $\begin{array}{l}1.742^{* * *} \\
{[0.030]}\end{array}$ & $\begin{array}{l}0.413^{* * *} \\
{[0.048]}\end{array}$ & $\begin{array}{c}-0.363^{* * *} \\
{[0.072]}\end{array}$ & $\begin{array}{c}-0.133^{* * *} \\
{[0.012]}\end{array}$ & $\begin{array}{c}-0.099^{* * *} \\
{[0.020]}\end{array}$ & 0.108 \\
\hline Model & $\chi_{1}^{2}$ & $p$-value ${ }_{1}$ & $\chi_{2}^{2}$ & $p$-value 21 & $p$-value 22 & \\
\hline \multicolumn{7}{|c|}{ Panel B: Test Statistics for Asymmetry in Investor Behaviour } \\
\hline (a) & 0.989 & 0.320 & $5.216^{* *}$ & 0.022 & 0.011 & \\
\hline (b) & 0.692 & 0.406 & $3.496^{* *}$ & 0.062 & 0.031 & \\
\hline
\end{tabular}

Notes:

a) This table reports estimated coefficients of the following regression model: $\operatorname{CSAD}_{t}=\gamma_{0}+\gamma_{1} D R_{m, t}+$ $\gamma_{2}(1-D) R_{m, t}+\gamma_{3} D R_{m, t}^{2}+\gamma_{4}(1-D) R_{m, t}^{2}+\varepsilon_{t}$, where $D=1$ for all observations with $R_{m, t}>0$, and 0 otherwise. Model (a) uses the return on an equally weighted portfolio as proxy for the market return $\left(R_{m, t}\right)$, while Model (b) uses the capitalization-weighted market index (VN index).

b) $\chi_{1}^{2}$ and $p$-value ${ }_{1}$ are statistics for the Wald test with the null hypothesis $H_{0}: \gamma_{1}=-\gamma_{2}$.

c) $\chi_{2}^{2}$ is the Chi-squared statistic for the Wald test of the hypothesis $H_{0}: \gamma_{3}=\gamma_{4} ; p$-value 21 is the $p$-value for the two-sided test (alternative hypothesis $H_{a}: \gamma_{3} \neq \gamma_{4}$ ), while $p$-value 22 is the $p$-value for the one-sided test (alternative hypothesis $H_{a}: \gamma_{3}<\gamma_{4}$ ).

d) Newey-West HAC standard errors are reported in square brackets.

e) ${ }^{*}{ }^{* *}$ and ${ }^{* * *}$ indicate statistical significance at the $10 \%, 5 \%$ and $1 \%$ respectively. 


\subsection{Impact of the Daily Price Limit}

In Vietnam, there are limits on the ranges of prices at which stocks can be traded on each day, imposed by the State Securities Commission (SSC). In particular, stock price volatility could not exceed a specified percentage compared to the closing values on the previous trading day. Once the trading price hits the limit, it will be bound at either the ceiling or floor price allowed. As reported by Chang et al. (2000), similar rules also exist in stock exchanges in Taiwan and South Korea, where the limits are set at $7 \%$ and $6 \%$ per day, respectively. The current daily price limit for the HOSE is 7\%; nevertheless, this has been adjusted quite regularly over the years by the SSC. Table 5 summarises how the limit has fluctuated since the exchange went into operation in 2000:

\section{Table 5}

Daily Price Limits for the HOSE from 2000.

\begin{tabular}{cccc}
\hline Date & Daily Price Limit & Date & Daily Price Limit \\
\hline $28 / 07 / 2000$ & $\pm 2 \%$ & $27 / 03 / 2008$ & $\pm 1 \%$ \\
$13 / 06 / 2001$ & $\pm 7 \%$ & $07 / 04 / 2008$ & $\pm 2 \%$ \\
$15 / 10 / 2001$ & $\pm 2 \%$ & $16 / 06 / 2008$ & $\pm 3 \%$ \\
$01 / 08 / 2002$ & $\pm 3 \%$ & $18 / 08 / 2008$ & $\pm 5 \%$ \\
$23 / 12 / 2002$ & $\pm 5 \%$ & $15 / 01 / 2013$ & $\pm 7 \%$ \\
\hline
\end{tabular}

Data source: Hoang Vu (2013)

It is possible for the daily price limits to affect the overall evidence in favour of herding. By limiting the daily price movements of stocks, the restrictions could have prevented individual stock prices from moving further away from each other, thereby lowering cross-section dispersion $\left(C S A D_{t}\right)$ and causing $\gamma_{2}$ estimates to be negative and significant when they should not be. To determine whether this is the case and conduct a robustness test for the results in Table 3, the Chang et al. (2000) model is re-estimated after all firm-day observations that reached the respective daily price limit have been excluded from the sample. 
The re-estimated results are presented in Table 6 . Out of a total of 474,403 firm-day observations in the original sample, 12,475 were excluded. Only the equally weighted portfolio is used as the market proxy, since the returns on the market index (weighted by market capitalisation and reported by Datastream) would incorporate individual stock returns that should have been excluded in this case. The coefficients on $R_{m, t}^{2}\left(\gamma_{2}\right)$ remain negative and significant at the $1 \%$ level ( -0.170 for the up market, and -0.115 for the down market). The findings regarding the existence of herd behaviour in the HOSE are robust to daily price limit tests.

A Wald test of the null hypothesis $H_{0}: \gamma_{2}^{U P}=\gamma_{2}^{\text {DOWN }}$ yields a $\chi^{2}$ statistic of 18.884 , leading to the rejection of $H_{0}$ at the $1 \%$ level. The daily price limit test not only confirms but also reinforces the finding of herding asymmetry between the up and down markets.

\section{Table 6}

Robustness Test with Daily Price Limits.

\begin{tabular}{ccccccc}
\hline $\begin{array}{c}\text { Up/Down } \\
\text { Market }\end{array}$ & $\begin{array}{c}\text { Constant } \\
\left(\gamma_{\mathbf{0}}\right)\end{array}$ & $\begin{array}{c}\left|\boldsymbol{R}_{\boldsymbol{m}, \boldsymbol{t}}\right| \\
\left(\gamma_{\mathbf{1}}\right)\end{array}$ & $\begin{array}{c}\boldsymbol{R}_{\boldsymbol{m}, \boldsymbol{t}}^{2} \\
\left(\gamma_{\mathbf{2}}\right)\end{array}$ & $\overline{\boldsymbol{R}^{\mathbf{2}}}$ & $\chi^{\mathbf{2}}$ & $\boldsymbol{p}$-value \\
\hline Up & $1.579^{* * *}$ & $0.517^{* * *}$ & $-0.170^{* * *}$ & 0.253 & & \\
& {$[0.029]$} & {$[0.047]$} & {$[0.010]$} & & & \\
Down & $1.639^{* * *}$ & $0.366^{* * *}$ & $-0.115^{* * *}$ & 0.098 & $18.884^{* * *}$ & 0.000 \\
& {$[0.035]$} & {$[0.081]$} & {$[0.021]$} & & & \\
\hline
\end{tabular}

Notes:

a) This table reports estimated coefficients of the following regression model: $\operatorname{CSAD}_{t}=\gamma_{0}+\gamma_{1}\left|R_{m, t}\right|+\gamma_{2} R_{m, t}^{2}+$ $\varepsilon_{t}$, where $\left|R_{m, t}\right|$ and $R_{m, t}^{2}$ respectively denote the absolute return and squared return on an equally weighted portfolio consisting of all stocks whose prices did not reach the daily limits at the close of trading. Out of a total of 474,403 firm-day observations, 12,475 were excluded from the sample.

b) In the up/down model, all observations are restricted to those with positive/negative $R_{m, t} \cdot \chi^{2}$ and $p$-value are statistics for the Wald test with the null hypothesis $H_{0}: \gamma_{2}^{U P}=\gamma_{2}^{D O W N}$.

c) Newey-West HAC standard errors are reported in square brackets.

d) ${ }^{*},{ }^{* *}$ and ${ }^{* * *}$ indicate statistical significance at the $10 \%, 5 \%$ and $1 \%$ respectively. 


\subsection{Impact of the Global Financial Crisis}

The recent global financial crisis took a heavy toll on economies all around the world, including Vietnam's. The effects of the crisis were inevitably reflected in the stock market. As shown in Figure 3, from an all-time high of 1,170.67 in March 2007, within less than two years, the VNIndex lost almost $80 \%$ of its values, plummeting to a 4-year low of 235.50 (equivalent to a return of $-56 \%$ per annum).

Devastating as it was for many investors, the crisis nonetheless presented a learning opportunity. Witnessing the drastic downfall, many investors might have gathered valuable experience about the stock market. Some may have decided to better equip themselves in financial theories, while others spend time developing more sophisticated and rational trading strategies. These actions are all expected to make the market more rational, in the sense that it reduces the magnitude of herding, or better yet, remove it all together. We test for this effect using following specification:

$$
\begin{aligned}
\operatorname{CSAD}_{t}=\gamma_{0}+\gamma_{1} D_{u} R_{m, t} & +\gamma_{2}\left(1-D_{u}\right) R_{m, t}+\gamma_{3} D_{u}\left(1-D_{a}\right) R_{m, t}^{2}+\gamma_{4}\left(1-D_{u}\right)\left(1-D_{a}\right) R_{m, t}^{2} \\
& +\gamma_{5} D_{u} D_{a} R_{m, t}^{2}+\gamma_{6}\left(1-D_{u}\right) D_{a} R_{m, t}^{2}+\varepsilon_{t}
\end{aligned}
$$

where $D_{u}$ is a dummy variable that equals 1 when $R_{m, t}>0$, and 0 otherwise; $D_{a}$ is a dummy variable that equals 1 for all observations after the break date, which is determined using a Quandt-Andrews test for structural break (Quandt, 1960; Andrews, 1993). ${ }^{11}$ This specification allows the investigation of any change in the herding behaviour following the crisis, while simultaneously allowing for asymmetry between the up and down markets. Herd behaviour before the crisis will be reflected in $\gamma_{3}$ and $\gamma_{4}$, while herd behaviour after the crisis will be reflected in $\gamma_{5}$ and $\gamma_{6}$.

Table 7 below summarises the estimation results based on Equation (14). Using either proxy for the market return, the break date was estimated to be 26 May 2011. It is evident from the table that there was a reduction in the magnitude of herd behaviour in the HOSE before and after the break date. All estimates for $\gamma_{5}$ and $\gamma_{6}$ are lower (in absolute value) than $\gamma_{3}$ and $\gamma_{4}$, and the differences are statistically significant, as evidenced by Wald test statistics $\chi_{u p}^{2}$ and $\chi_{\text {down }}^{2}$, all

\footnotetext{
${ }^{11}$ We thank an anonymous referee's suggestion on this approach.
} 
significant at the $1 \%$ level. Estimates of post-crisis herding in down market days $\left(\gamma_{6}\right)$ are either significant only at the $10 \%$ level ( -0.038 in model b), or even insignificant ( -0.021 in model a). These results reveal considerable reduction in herd mentality, and even though the reduction is not sufficient to render the overall herding insignificant, it suggests that the market is moving towards rationality and higher efficiency following the recent financial crisis.

The improvement of the market can be demonstrated by calculating $R^{\max }$ and $R^{\text {min }}$ - the highest and lowest value of $R_{m, t}$ for which return dispersion is still expected to increase with $\left|R_{m, t}\right|$. These values are the roots of the first derivative of $C S A D_{t}$ with respect to $R_{m, t}$ when $D_{u}$ is set to 1 and 0 , respectively. Accordingly, their formulas are $R^{\max }=-\frac{\gamma_{1}}{2\left[\gamma_{3}\left(1-D_{a}\right)+\gamma_{5} D_{a}\right]}$ and $R^{\min }=$ $-\frac{\gamma_{2}}{2\left[\left(1-D_{a}\right) \gamma_{4}+\gamma_{6} D_{a}\right]}$. The stronger the herding is, the less the market needs to swing for $\operatorname{CSAD}_{t}$ to decrease instead of increasing with $R_{m, t}$, and the closer $R^{\max }$ and $R^{\min }$ will be to zero.

The estimated values are presented in Panel B of Table 7. The models suggest that before the crisis, on up market days, herding starts manifesting itself (in the sense that it causes $\operatorname{CSAD}_{t}$ to decrease with $\left.R_{m, t}\right)$ as early as when $R_{m, t}$ reaches around $1.4 \%(1.429 \%$ and $1.395 \%)$, whereas during down periods, the same effect surfaces as $R_{m, t}$ falls below $-1.5 \%(-1.536 \%$ and $-1.591 \%$ ). After the crisis, on the other hand, the up market requires a return of $2.349 \%$ and above to exhibit a downwards trend of return dispersion, and the down market needs to fall by at least $4 \%(-4.483 \%$ and $-7.940 \%)$ before $C S A D_{t}$ starts falling. ${ }^{12}$

These findings are illustrated in Figure 6, in which the fitted values of $\operatorname{CSAD}_{t}$ before and after the crisis are respectively represented by the dashed and solid curves. It is clear that the solid curve is above the dash one in both the up and down markets, which visualises the reduction in the magnitude of herding (the difference between $\gamma_{3}$ and $\gamma_{5}$, or $\gamma_{4}$ and $\gamma_{6}$ given the same level of

\footnotetext{
${ }^{12}$ Following a comment made by an anonymous referee, we also run yearly regressions for Equation (14) as a robustness check. The results show that, following 2011, there is an upward trend in the herding coefficients for both markets (the coefficients became less negative or even positive), which is consistent with the results reported in Table 7 (that there is a significant reduction in the magnitude of herding following the crisis).
} 
$\left.R_{m, t}\right)$. The continued existence of herd mentality following the crisis is reflected in the shape of the solid curve. Rational asset pricing theory suggests a linear relationship between $\operatorname{CSAD}_{t}$ and $\left|R_{m, t}\right|$ when herding does not exist, which would transform into a V-shaped curve (as opposed to two inverted U's) when $C S A D_{t}$ is plotted against $R_{m, t}$.

$R^{\max }$ and $R^{\min }$ are also depicted in Figure 6, with the red dashed vertical lines representing the Before values, and the blue ones representing the After values. ${ }^{13}$ Not only is it clear that the After lines are further away from the vertical axis $\left(R_{m, t}=0\right)$, it is also highly noticeable that, compared to the up mark counterpart, the After (blue) line is further away from their corresponding Before (red) lines when the market is down. This indicates that the change in herd behaviour is more profound in the down market compared to the up market. One possible explanation is that the crisis has filtered out short-term investors and thus has retained relatively more long-term investors in the market, who are less likely to hurriedly sell their shares in down market. Investor optimism could also contribute to this result. Believing that the market is recovering from the crisis, investors might have developed a preference for buying shares whose prices are increasing, while at the same time refraining from selling stocks when prices are declining.

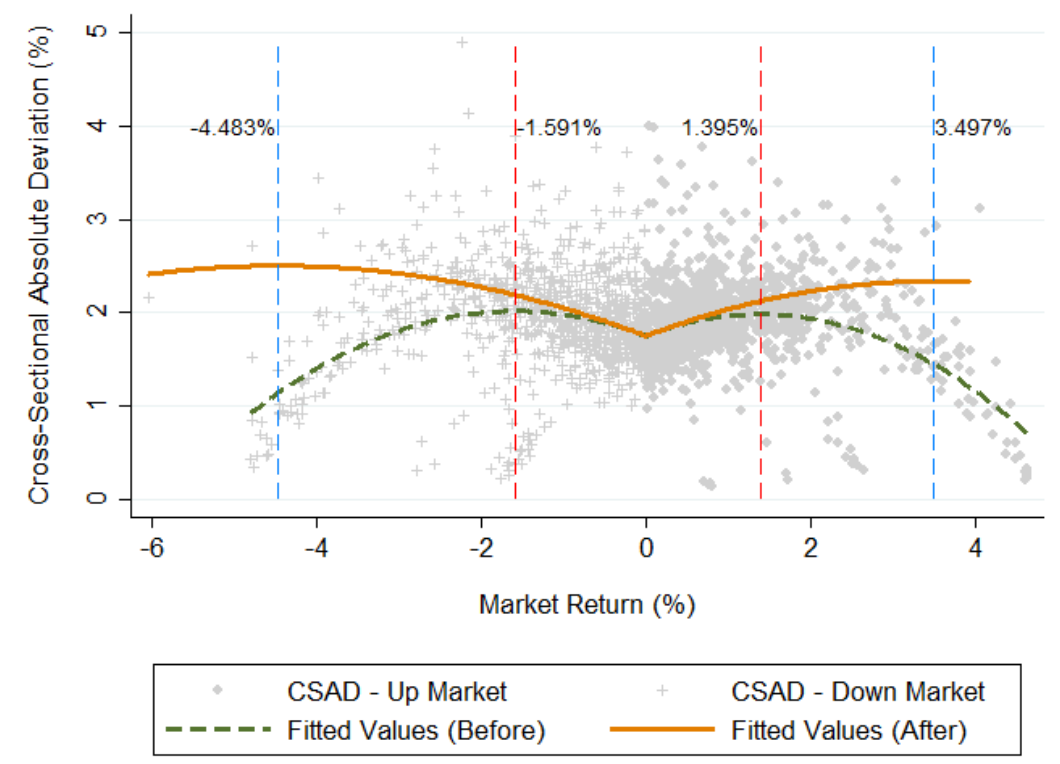

Figure 6. Magnitude of Herding Before and After the Financial Crisis.

\footnotetext{
${ }^{13}$ To save space, in Figure 6 we report only results using capitalization-weighted market index (Model b in Table 7). Similar graph is obtained for the equally weighted market index case and is available upon request.
} 


\section{Table 7}

Effects on Herd Behaviour of the Global Financial Crisis.

\begin{tabular}{|c|c|c|c|c|c|c|c|c|}
\hline Model & $\begin{array}{c}\text { Constant } \\
\left(\gamma_{0}\right)\end{array}$ & $\begin{array}{c}D_{u} R_{m, t} \\
\quad\left(\gamma_{1}\right) \\
\end{array}$ & $\begin{array}{c}\left(1-D_{u}\right) R_{m, t} \\
\left(\gamma_{2}\right)\end{array}$ & $\begin{array}{c}D_{u}\left(1-D_{a}\right) R_{m, t}^{2} \\
\left(\gamma_{3}\right)\end{array}$ & $\begin{array}{c}\left(1-D_{u}\right)\left(1-D_{a}\right) R_{m, t}^{2} \\
\left(\gamma_{4}\right)\end{array}$ & $\begin{array}{c}D_{u} D_{a} R_{m, t}^{2} \\
\quad\left(\gamma_{5}\right)\end{array}$ & $\begin{array}{c}\left(1-D_{u}\right) D_{a} R_{m, t}^{2} \\
\left(\gamma_{6}\right)\end{array}$ & $\overline{R^{2}}$ \\
\hline \multicolumn{9}{|c|}{ Panel A: Regression Results } \\
\hline \multirow[t]{2}{*}{ (a) } & $1.678^{* * *}$ & $0.414^{* * *}$ & $-0.341^{* * *}$ & $-0.145^{* * *}$ & $-0.111^{* * *}$ & $-0.088^{* * *}$ & -0.021 & 0.224 \\
\hline & [0.024] & [0.054] & [0.067] & [0.013] & [0.015] & [0.029] & {$[0.026]$} & \\
\hline \multirow[t]{2}{*}{ (b) } & $1.751^{* * *}$ & $0.337^{* * *}$ & $-0.337^{* * *}$ & $-0.121^{* * *}$ & $-0.106^{* * *}$ & $-0.048^{* *}$ & $-0.038^{*}$ & 0.167 \\
\hline & [0.028] & [0.052] & {$[0.061]$} & [0.013] & [0.014] & {$[0.023]$} & {$[0.020]$} & \\
\hline Model & Break Date & $\chi_{\mathrm{up}}^{2}$ & $\chi_{\text {down }}^{2}$ & $R_{B e f o r e}^{\max }$ & $R_{\text {After }}^{\max }$ & $R_{B e f o r e}^{\min }$ & $R_{\text {After }}^{\min }$ & \\
\hline \multicolumn{9}{|c|}{ Panel B: Impact of the Global Financial Crisis } \\
\hline (a) & $26 / 5 / 2011$ & $9.440^{* * *}$ & $52.047^{* * *}$ & 1.429 & 2.349 & -1.536 & -7.940 & \\
\hline (b) & $26 / 5 / 2011$ & $26.954^{* * *}$ & $52.490^{* * *}$ & 1.395 & 3.497 & -1.591 & -4.483 & \\
\hline
\end{tabular}

Notes:

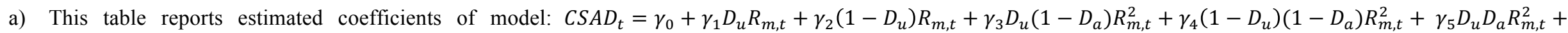

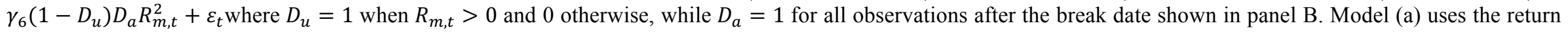
on an equally weighted portfolio as proxy for the market return $\left(R_{m, t}\right)$, while Model (b) uses the capitalization-weighted market index.

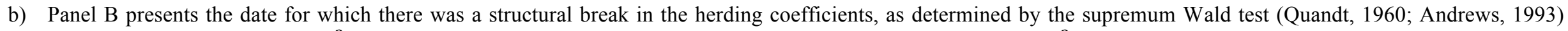

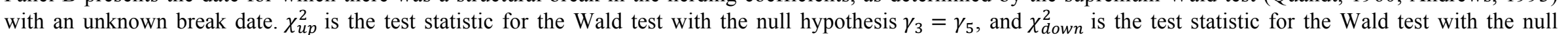
hypothesis $\gamma_{4}=\gamma_{6}$.

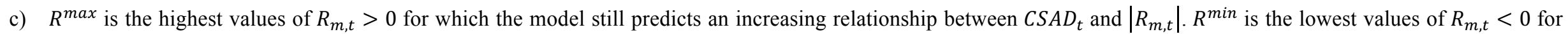

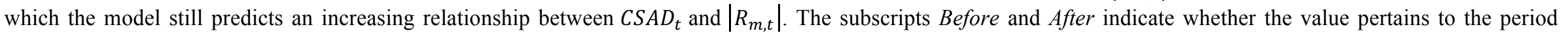
before or after the corresponding break date.

d) Newey-West HAC standard errors are reported in square brackets.

e) ${ }^{*},{ }^{* *}$ and ${ }^{* * *}$ indicate statistical significance at the $10 \%, 5 \%$ and $1 \%$ respectively. 


\subsection{Fundamental vs Non-fundamental Herding}

Panels A of Tables 8 and 9 present the results for testing for fundamental and non-fundamental herding as proposed in Section 2.3. Table 8 shows results of the decomposition step, where we follow Galariotis et al. (2015)'s approach described in Equation (7) to decompose the total $\operatorname{CSAD}_{t}$ into $C S A D_{F U N D, t}$ and $C S A D_{N O N F U N D, t}$ respectively for fundamental and non-fundamental components. Table 9 reports the regression results obtained when $\operatorname{CSAD}_{F U N D, t}$ and $C S A D_{N O N F U N D, t}$ are regressed against market return factors, i.e., equations (8) and (9). ${ }^{14}$

\section{Table 8}

Decomposing Total $C S A D_{t}$ to $C S A D_{F U N D, t}$ and $\operatorname{CSAD}_{N O N F U N D, t}$.

\begin{tabular}{|c|c|c|c|c|c|c|}
\hline Model & $\begin{array}{c}\text { Constant } \\
\left(\beta_{0}\right)\end{array}$ & $\begin{array}{c}R_{m, t}-R_{f} \\
\left(\beta_{1}\right)\end{array}$ & $\begin{array}{c}S M B_{t} \\
\left(\beta_{2}\right)\end{array}$ & $\begin{array}{c}H M L_{t} \\
\left(\beta_{3}\right) \\
\end{array}$ & $\begin{array}{c}M^{M O M_{t}} \\
\left(\beta_{4}\right)\end{array}$ & $\overline{R^{2}}$ \\
\hline \multicolumn{7}{|c|}{ Panel A: Galariotis et al. (2015)'s Approach } \\
\hline VN Index for $R_{m, t}$ & $\begin{array}{l}1.907^{* * *} \\
{[0.021]}\end{array}$ & $\begin{array}{l}-0.009 \\
{[0.014]}\end{array}$ & $\begin{array}{c}0.049 \\
{[0.036]}\end{array}$ & $\begin{array}{c}0.031 \\
{[0.027]}\end{array}$ & $\begin{array}{c}0.019 \\
{[0.016]}\end{array}$ & 0.005 \\
\hline VN Index for $R_{m, t}$ & $\begin{array}{l}1.906^{* * *} \\
{[0.021]}\end{array}$ & & $\begin{array}{c}0.055 \\
{[0.035]}\end{array}$ & $\begin{array}{c}0.030 \\
{[0.027]}\end{array}$ & & 0.003 \\
\hline Equally Weighted Portfolio for $R_{m, t}$ & $\begin{array}{l}1.832^{* * *} \\
{[0.020]}\end{array}$ & $\begin{array}{c}-0.012 \\
{[0.014]}\end{array}$ & $\begin{array}{l}0.081^{* * *} \\
{[0.028]}\end{array}$ & $\begin{array}{l}0.059^{* *} \\
{[0.026]}\end{array}$ & $\begin{array}{c}0.019 \\
{[0.015]}\end{array}$ & 0.013 \\
\hline Equally Weighted Portfolio for $R_{m, t}$ & $\begin{array}{l}1.832^{* * *} \\
{[0.020]}\end{array}$ & & $\begin{array}{l}0.082^{* * *} \\
{[0.029]}\end{array}$ & $\begin{array}{l}0.052^{* *} \\
{[0.024]}\end{array}$ & & 0.010 \\
\hline Model & $\begin{array}{c}\text { Constant } \\
\left(\delta_{0}\right) \\
\end{array}$ & $\begin{array}{c}\left|R_{m, t}-R_{f}\right| \\
\left(\delta_{1}\right)\end{array}$ & $\begin{array}{c}\left|S M B_{t}\right| \\
\left(\delta_{2}\right)\end{array}$ & $\begin{array}{c}\left|H M L_{t}\right| \\
\left(\delta_{3}\right)\end{array}$ & $\begin{array}{c}\left|M_{0} M_{t}\right| \\
\left(\delta_{4}\right)\end{array}$ & $\overline{R^{2}}$ \\
\hline \multicolumn{7}{|l|}{ Panel B: Absolute Value Approach } \\
\hline VN Index for $R_{m, t}$ & $\begin{array}{l}1.608^{* * *} \\
{[0.035]}\end{array}$ & $\begin{array}{c}-0.084^{* * *} \\
{[0.016]}\end{array}$ & $\begin{array}{l}0.367^{* * *} \\
{[0.036]}\end{array}$ & $\begin{array}{l}0.283^{* * *} \\
{[0.027]}\end{array}$ & $\begin{array}{l}0.070^{* * *} \\
{[0.017]}\end{array}$ & 0.242 \\
\hline Equally Weighted Portfolio for $R_{m, t}$ & $\begin{array}{l}1.565^{* * *} \\
{[0.033]}\end{array}$ & $\begin{array}{c}-0.104^{* * *} \\
{[0.015]}\end{array}$ & $\begin{array}{l}0.310^{* * *} \\
{[0.029]}\end{array}$ & $\begin{array}{c}0.298^{* * *} \\
{[0.025]}\end{array}$ & $\begin{array}{l}0.075^{* * *} \\
{[0.015]}\end{array}$ & 0.264 \\
\hline
\end{tabular}

\section{Notes:}

a) Panel $\mathrm{A}$ of this table reports estimated coefficients of the following regression model: $\operatorname{CSAD}_{t}=\beta_{0}+\beta_{1}\left(R_{m, t}-R_{f}\right)+$ $\beta_{2} S M B_{t}+\beta_{3} H M L_{t}+\beta_{4} M O M_{t}+\varepsilon_{t}$. Panel $\mathrm{B}$ of this table reports estimated coefficients of the following regression model: $C S A D_{t}=\delta_{0}+\delta_{1}\left|R_{m, t}-R_{f}\right|+\delta_{2}\left|S M B_{t}\right|+\delta_{3}\left|H M L_{t}\right|+\delta_{4}\left|M O M_{t}\right|+\varepsilon_{t}$.

b) From these equations, the total $C S A D_{t}$ is decomposed into a "non-fundamental" component $\left(C S A D_{N O N F U N D, t}\right)$ captured by $\widehat{\varepsilon_{t}}$. The "fundamental" component $\left(C S A D_{F U N D, t}\right)$ is defined as the estimated $C S A D_{t}$.

c) Newey-West HAC standard errors are reported in square brackets.

d) ${ }^{*},{ }^{* *}$ and ${ }^{* * *}$ indicate statistical significance at the $10 \%, 5 \%$ and $1 \%$ respectively.

\footnotetext{
${ }^{14} \mathrm{We}$ collected data on the market value and book-to-market ratio for each stock from Datastream to construct the
} $H M L, S M B$ and $M O M$ factors, following the approaches in Fama \& French (1995) and Calhart (1997). 
Note that all equations in Panel A of Table 8, following Galariotis et al. (2015)'s approach, have low explanatory powers (with $\overline{R^{2}}$ ranging from 0.003 to 0.013 ) and factors that are insignificant even at the $10 \%$ level. Motivated by the poor performance of the four-factor model in explaining return dispersions, we improve the model by noting that $C S A D_{t}$, by construction, responds to the absolute value of factors. To illustrate, consider the $S M B$ factor, which measures the difference between the returns on a portfolio of "small" stocks and a portfolio of "big" stocks. When "small" stock returns deviate (either positively or negatively) from "big" stock returns, the absolute value of $S M B_{t}$ rises, and so should $C S A D_{t}$. Therefore, it makes more sense to use absolute value of $S M B_{t}$ as a regressor. The same argument applies to the other factors. As such, we suggest the following equation for decomposition in lieu of equation (7):

$$
C S A D_{t}=\delta_{0}+\delta_{1}\left|R_{m, t}-R_{f}\right|+\delta_{2}\left|S M B_{t}\right|+\delta_{3}\left|H M L_{t}\right|+\delta_{4}\left|M O M_{t}\right|+\varepsilon_{t}
$$

We rerun the equations applying this modification and obtain the results in Table 8 Panel B (absolute value approach), which exhibit considerable improvements over the models in Panel A as indicated by higher $\overline{R^{2}}$ and significant estimated coefficients at the $1 \%$ level.

Turning to the herding regression, when fundamental $\left(C S A D_{F U N D, t}\right)$ and non-fundamental $\left(C S A D_{N O N F U N D, t}\right)$ components are obtained by following Galariotis et al. (2015) approach, the herding coefficients $\left(\gamma_{3}\right.$ and $\left.\gamma_{4}\right)$ for $C S A D_{F U N D, t}$ as reported in Panel A of Table 9 are all negligible in magnitude and mostly insignificant. In contrast, all herding coefficients for $C S A D_{N O N F U N D, t}$ are statistically significant at the $1 \%$ level ranging from -0.136 to -0.417 . We obtain similar results when we drop two (insignificant) factors $\left(R_{m, t}-R_{f}\right.$ and $\left.M O M_{t}\right)$ in the decomposition step. In Panel B Table 9, when $\operatorname{CSAD}_{F U N D, t}$ and $C S A D_{N O N F U N D, t}$ are obtained by using absolute value approach, the fundamental herding coefficients $\left(\gamma_{3}\right.$ and $\left.\gamma_{4}\right)$ are now negative and significant at $1 \%$ (ranging from -0.022 to -0.048 ), which incidentally have led to a reduction in the magnitude of non-fundamental herding $(-0.079$ to -0.111$)$. Consequently, by using absolute values for regressors in equation (15), we are able to successfully extract the fundamental driven component of $C S A D_{t}$, and subsequently uncover both fundamental and nonfundamental herding. This reinforces our findings of herd behaviour, since even after conditioning on fundamental information (thus factoring out the so-called "spurious" herding), 
we still find a non-linear, negative relationship between return dispersion and market return in Vietnam. Note that, while the focus is not on herding asymmetry, we still include both $D R_{m, t}^{2}$ and $(1-D) R_{m, t}^{2}$ terms on the right hand sides to allow for herding asymmetry. The estimated results confirm that the result of stronger herding in the up market remains and it does not depend on whether it is fundamental or non-fundamental herding. 


\section{Table 9}

Testing for Fundamental and Non-Fundamental Herding.

\begin{tabular}{|c|c|c|c|c|c|c|}
\hline Dependent Variable & $\begin{array}{c}\text { Constant } \\
\left(\gamma_{0}\right) \\
\end{array}$ & $\begin{array}{c}D R_{m, t} \\
\left(\gamma_{1}\right) \\
\end{array}$ & $\begin{array}{c}(1-D) R_{m, t} \\
\left(\gamma_{2}\right)\end{array}$ & $\begin{array}{c}D R_{m, t}^{2} \\
\left(\gamma_{3}\right) \\
\end{array}$ & $\begin{array}{c}(1-D) R_{m, t}^{2} \\
\left(\gamma_{4}\right)\end{array}$ & $\overline{R^{2}}$ \\
\hline \multicolumn{6}{|l|}{ Panel A: Galariotis et al. 2015 Approach } & \\
\hline$C S A D_{F U N D, t}($ from 2-factor Model) & $\begin{array}{l}1.909^{* * *} \\
{[0.001]}\end{array}$ & $\begin{array}{l}-0.004^{*} \\
{[0.002]}\end{array}$ & $\begin{array}{l}-0.003 \\
{[0.002]}\end{array}$ & $\begin{array}{c}0.000 \\
{[0.001]}\end{array}$ & $\begin{array}{l}-0.001 \\
{[0.001]}\end{array}$ & 0.016 \\
\hline$C S A D_{F U N D, t}($ from 4-factor Model) & $\begin{array}{l}1.906^{* * *} \\
{[0.002]}\end{array}$ & $\begin{array}{l}-0.008^{* * *} \\
{[0.003]}\end{array}$ & $\begin{array}{l}-0.015^{* * *} \\
{[0.003]}\end{array}$ & $\begin{array}{l}-0.000 \\
{[0.001]}\end{array}$ & $\begin{array}{l}-0.001 \\
{[0.001]}\end{array}$ & 0.176 \\
\hline$C S A D_{N O N F U N D, t}($ from 2-factor Model) & $\begin{array}{l}-0.169^{* * *} \\
{[0.030]}\end{array}$ & $\begin{array}{l}0.422^{* * *} \\
{[0.047]}\end{array}$ & $\begin{array}{l}-0.362^{* * *} \\
{[0.072]}\end{array}$ & $\begin{array}{c}-0.137^{* * *} \\
{[0.012]}\end{array}$ & $\begin{array}{c}-0.100^{* * *} \\
{[0.020]}\end{array}$ & 0.115 \\
\hline$C S A D_{N O N F U N D, t}($ from 4-factor Model) & $\begin{array}{l}-0.165^{* * *} \\
{[0.030]}\end{array}$ & $\begin{array}{l}0.425^{* * *} \\
{[0.048]}\end{array}$ & $\begin{array}{c}-0.350^{* * *} \\
{[0.072]}\end{array}$ & $\begin{array}{l}-0.136^{* * *} \\
{[0.012]}\end{array}$ & $\begin{array}{l}-0.100^{* * *} \\
{[0.020]}\end{array}$ & 0.114 \\
\hline & \multicolumn{6}{|c|}{ Equally Weighted Portfolio for $R_{m, t}$} \\
\hline$C S A D_{F U N D, t}($ from 2-factor Model) & $\begin{array}{l}1.830^{* * *} \\
{[0.002]}\end{array}$ & $\begin{array}{l}0.019^{* * *} \\
{[0.004]}\end{array}$ & $\begin{array}{l}-0.002 \\
{[0.004]}\end{array}$ & $\begin{array}{c}-0.004^{* * *} \\
{[0.001]}\end{array}$ & $\begin{array}{l}-0.001 \\
{[0.001]}\end{array}$ & 0.028 \\
\hline$C S A D_{F U N D, t}($ from 4-factor Model) & $\begin{array}{l}1.825^{* * *} \\
{[0.002]}\end{array}$ & $\begin{array}{l}0.017^{* * *} \\
{[0.005]}\end{array}$ & $\begin{array}{c}-0.015^{* * *} \\
{[0.004]}\end{array}$ & $\begin{array}{l}-0.005^{* * *} \\
{[0.001]}\end{array}$ & $\begin{array}{l}-0.001 \\
{[0.001]}\end{array}$ & 0.032 \\
\hline$C S A D_{N O N F U N D, t}($ from 2-factor Model) & $\begin{array}{c}-0.170^{* * *} \\
{[0.023]}\end{array}$ & $\begin{array}{l}0.458^{* * *} \\
{[0.043]}\end{array}$ & $\begin{array}{c}-0.417^{* * *} \\
{[0.064]}\end{array}$ & $\begin{array}{c}-0.155^{* * *} \\
{[0.010]}\end{array}$ & $\begin{array}{c}-0.122^{* * *} \\
{[0.016]}\end{array}$ & 0.176 \\
\hline$C S A D_{N O N F U N D, t}($ from 4-factor Model) & $\begin{array}{l}-0.166^{* * *} \\
{[0.023]}\end{array}$ & $\begin{array}{l}0.461^{* * *} \\
{[0.043]}\end{array}$ & $\begin{array}{l}-0.404^{* * *} \\
{[0.065]}\end{array}$ & $\begin{array}{l}-0.153^{* * *} \\
{[0.010]}\end{array}$ & $\begin{array}{l}-0.122^{* * *} \\
{[0.016]}\end{array}$ & 0.174 \\
\hline \multicolumn{7}{|l|}{ Panel B: Absolute Value Approach } \\
\hline$C S A D_{F U N D, t}($ from 4-factor Model) & $\begin{array}{l}1.917^{* * *} \\
{[0.013]}\end{array}$ & $\begin{array}{l}0.049^{* *} \\
{[0.020]}\end{array}$ & $\begin{array}{l}-0.042^{*} \\
{[0.025]}\end{array}$ & $\begin{array}{l}-0.029^{* * *} \\
{[0.005]}\end{array}$ & $\begin{array}{c}-0.022^{* * *} \\
{[0.007]}\end{array}$ & 0.059 \\
\hline$C S A D_{N O N F U N D, t}($ from 4-factor Model) & $\begin{array}{c}-0.177^{* * *} \\
{[0.024]}\end{array}$ & $\begin{array}{l}0.368^{* * *} \\
{[0.039]}\end{array}$ & $\begin{array}{c}-0.323^{* * *} \\
{[0.058]}\end{array}$ & $\begin{array}{c}-0.107^{* * *} \\
{[0.010]}\end{array}$ & $\begin{array}{c}-0.079^{* * *} \\
{[0.015]}\end{array}$ & 0.084 \\
\hline & \multicolumn{6}{|c|}{ Equally Weighted Portfolio for $R_{m, t}$} \\
\hline$C S A D_{F U N D, t}$ (from 4-factor Model) & $\begin{array}{l}1.831^{* * *} \\
{[0.010]}\end{array}$ & $\begin{array}{l}0.106^{* * *} \\
{[0.021]}\end{array}$ & $\begin{array}{c}-0.075^{* * *} \\
{[0.022]}\end{array}$ & $\begin{array}{c}-0.048^{* * *} \\
{[0.005]}\end{array}$ & $\begin{array}{c}-0.036^{* * *} \\
{[0.006]}\end{array}$ & 0.121 \\
\hline$C S A D_{N O N F U N D, t}($ from 4-factor Model) & $\begin{array}{c}-0.172^{* * *} \\
{[0.020]}\end{array}$ & $\begin{array}{l}0.372^{* * *} \\
{[0.035]}\end{array}$ & $\begin{array}{c}-0.344^{* * *} \\
{[0.054]}\end{array}$ & $\begin{array}{c}-0.111^{* * *} \\
{[0.008]}\end{array}$ & $\begin{array}{c}-0.087^{* * *} \\
{[0.013]}\end{array}$ & 0.107 \\
\hline
\end{tabular}

\section{Notes:}

a) This table reports estimated coefficients of the following regression model: $C S A D_{t}=\gamma_{0}+\gamma_{1} D R_{m, t}+\gamma_{2}(1-D) R_{m, t}+\gamma_{3} D R_{m, t}^{2}+\gamma_{4}(1-D) R_{m, t}^{2}+\varepsilon_{t}$, where $D=1$ for all observations with $R_{m, t}>0$, and 0 otherwise.

b) 4-factor model refers to models where $C S A D_{t}$ is separated into the "fundamental" and "non-fundamental" components using 4 factors (Fama-French \& Momentum). 2-factor model refers to models where $C S A D_{t}$ is separated into the "fundamental" and "non-fundamental" components using only two factors $S M B_{t}$ and $H M L_{t}$ given that other factors are not significant.

c) Newey-West HAC standard errors are reported in square brackets.

d) ${ }^{*},{ }^{* *}$ and ${ }^{* * *}$ indicate statistical significance at the $10 \%, 5 \%$ and $1 \%$ respectively. 


\subsection{Within- and Between-Group Herding}

Results of tests for within- and between group herding are reported in Table 10, with Panel A reporting results for equation (10) (positive alpha stocks), and Panel B for equation (11) (negative alpha stocks). ${ }^{15}$ Model (a) includes all stocks regardless of statistical significance of the estimated alphas. Model (b) excludes all stocks with alphas that are not statistically significant at the $10 \%$ level.

\section{Table 10}

Testing for Within- and Between-Group Herding.

\begin{tabular}{|c|c|c|c|c|c|c|c|}
\hline Model & $\begin{array}{c}\text { Constant } \\
\left(\gamma_{0}\right)\end{array}$ & $\begin{array}{c}\boldsymbol{R}_{+m, t} \\
\left(\gamma_{1}\right)\end{array}$ & $\begin{array}{c}\left|R_{+m, t}\right| \\
\left(\gamma_{2}\right)\end{array}$ & $\begin{array}{c}R_{+m, t}^{2} \\
\left(\gamma_{3}\right)\end{array}$ & $\begin{array}{c}R_{-m, t}^{2} \\
\left(\gamma_{4}\right)\end{array}$ & $\begin{array}{c}C S A D_{-, t} \\
\left(\gamma_{5}\right)\end{array}$ & $\overline{R^{2}}$ \\
\hline \multicolumn{8}{|c|}{ Panel A: Positive Alpha Stocks Regression } \\
\hline (a) & $\begin{array}{l}0.413^{* * *} \\
{[0.095]}\end{array}$ & $\begin{array}{l}-0.011 \\
{[0.007]}\end{array}$ & $\begin{array}{l}0.275^{* * *} \\
{[0.039}\end{array}$ & $\begin{array}{c}-0.133^{* * *} \\
{[0.012]}\end{array}$ & $\begin{array}{l}0.064^{* * *} \\
{[0.010]}\end{array}$ & $\begin{array}{l}0.659^{* * *} \\
{[0.055]}\end{array}$ & 0.588 \\
\hline (b) & $\begin{array}{l}1.224^{* * *} \\
{[0.060]}\end{array}$ & $\begin{array}{l}-0.013 \\
{[0.009]}\end{array}$ & $\begin{array}{l}0.420^{* * *} \\
{[0.054]}\end{array}$ & $\begin{array}{c}-0.138^{* * *} \\
{[0.015]}\end{array}$ & $\begin{array}{l}0.012^{* * *} \\
{[0.004]}\end{array}$ & $\begin{array}{l}0.171^{* * *} \\
{[0.023]}\end{array}$ & 0.186 \\
\hline Model & $\begin{array}{c}\text { Constant } \\
\left(\gamma_{6}\right)\end{array}$ & $\begin{array}{c}R_{-m, t} \\
\left(\gamma_{7}\right)\end{array}$ & $\begin{array}{c}\left|R_{-m, t}\right| \\
\left(\gamma_{8}\right)\end{array}$ & $\begin{array}{c}R_{-m, t}^{2} \\
\left(\gamma_{9}\right)\end{array}$ & $\begin{array}{c}R_{+m, t}^{2} \\
\left(\gamma_{10}\right)\end{array}$ & $\begin{array}{c}C S A D_{+, t} \\
\left(\gamma_{11}\right)\end{array}$ & $\overline{R^{2}}$ \\
\hline \multicolumn{8}{|c|}{ Panel B: Negative Alpha Stocks Regression } \\
\hline (a) & $\begin{array}{c}0.549^{* * *} \\
{[0.058]}\end{array}$ & $\begin{array}{c}0.007 \\
{[0.006]}\end{array}$ & $\begin{array}{l}0.149^{* * *} \\
{[0.035]}\end{array}$ & $\begin{array}{c}-0.125^{* * *} \\
{[0.011]}\end{array}$ & $\begin{array}{l}0.071^{* * *} \\
{[0.008]}\end{array}$ & $\begin{array}{l}0.718^{* * *} \\
{[0.036]}\end{array}$ & 0.581 \\
\hline (b) & $\begin{array}{l}0.833^{* * * *} \\
{[0.107]}\end{array}$ & $\begin{array}{c}0.003 \\
{[0.016]}\end{array}$ & $\begin{array}{l}0.519^{* * *} \\
{[0.071]}\end{array}$ & $\begin{array}{c}-0.157^{* * *} \\
{[0.015]}\end{array}$ & $\begin{array}{c}0.001 \\
{[0.008]}\end{array}$ & $\begin{array}{l}0.375^{* * *} \\
{[0.049]}\end{array}$ & 0.194 \\
\hline
\end{tabular}

Notes:
a) Panel A reports estimated coefficients for equation (10). Panel B reports estimated coefficients for equation (11).
b) $+/-$ refers to the measures $\left(C S A D_{t}, R_{m, t}\right)$ formed using a portfolio of stocks with positive/negative alphas ( $\alpha$ 's).
c) Models (a) use portfolios formed of all stocks available. Models (b) only allow portfolios of stocks whose alphas are statistically significant at the $10 \%$ level.
d) Newey-West HAC standard errors are reported in square brackets.
e) ${ }^{*},{ }^{* *}$ and ${ }^{* * *}$ indicate statistical significance at the $10 \%, 5 \%$ and $1 \%$ respectively.

It is clear that there existed within-group herding in the market, for the corresponding coefficients $\left(\gamma_{3}\right.$ and $\left.\gamma_{9}\right)$ are negative and statistically significant, even at the $1 \%$ level. Thus, under our assumption that positive alpha stocks tend to be held by arbitrageurs and noise traders are more likely to trade on negative alpha stocks, the results imply that both groups of investors

\footnotetext{
${ }^{15}$ Alpha values used to construct the relevant positive/negative alpha portfolios were calculated on yearly basis for the period 2007-2015. We thank an anonymous referee's suggestion on this approach.
} 
engage in herd behaviour among themselves, although for possibly different reasons (fund managers might have wanted to preserve their reputation or compensation, while noise traders could have irrationally mimicked others' actions).

Between-group herding, on the other hand, is less apparent. The estimated between-group herding coefficient for positive alpha stocks $\left(\gamma_{4}\right)$ are significant at the $1 \%$ level, but are positive (0.064 and 0.012). This is evidence against herding, and is consistent with the assumption that arbitrageurs are sophisticated traders, i.e., arbitrageurs are not infected by market jitters easily. One possible explanation for this estimated result is that, when arbitrageurs realise that noise traders are forming herds due to pseudo-signals, instead of following arbitrage strategy to bring asset prices back to their fundamental values, they decide to create even more mixed signals to take advantage on the situation. Consequently, arbitrageurs do not simply sell or buy their existing shares (of positive alpha stocks) arbitrarily. Instead, they refer to their strategies and adjust their holdings accordingly, leading to changes to the prices of positive alpha stocks of various degrees, thereby raising rather than lowering $C S A D_{+, t}$.

The between-group herding coefficient for negative alpha stocks $\left(\gamma_{10}\right)$, meanwhile, is positive (0.071) and significant at the $1 \%$ level for model (a), and insignificant at the $10 \%$ level in model (b). The fact that we no longer obtain a significant $\gamma_{10}$ when we apply a stricter definition of negative alpha stocks supports the notion that it is this more strictly defined portfolio that resembles more closely the typical holdings of noise traders in the market. This also suggests that noise traders are not as sophisticated as arbitrageurs. Since they are unable to identify positive alpha stocks and often trade without much information, it is not surprising that their stock return dispersion is not responsive to the returns on the positive alpha stock portfolio.

The counterpart $C S A D_{t}$ terms $\left(C S A D_{-, t}\right.$ in panel A and $C S A D_{+, t}$ in panel B) are included to allow for the possibility of co-movements of return dispersion between groups of stocks, as previously documented by Chang \& Zheng (2010) and Galariotis et al. (2015). In addition, as these terms are correlated with the counterpart squared portfolio return $\left(R_{-m, t}^{2}\right.$ and $R_{+m, t}^{2}$, respectively), if 
these two terms were not included, our model would lead to biased estimates of $\gamma_{4}$ and $\gamma_{10}$, this resulting in misleading conclusions on between-group herding. As shown in Table 10, both $\gamma_{5}$ and $\gamma_{11}$ are significant at the $1 \%$ and positive. This is consistent with our previous conjecture that, heterogeneous investors interact with each other, even though they may not herd from their counterpart. A possible interpretation for the positive estimates is the fundamental herding observed in Section 3.5. As rational investors (arbitrageurs) face the same fundamental information, they arrive at the same investing decisions, which results in a lower $C S A D_{+, t}$. Facing the same information, noise traders, however, may disregard it and choose to follow the market consensus, thus driving down $C S A D_{-, t}$. It is this combination that yields a positive relationship between the two CSAD series.

\section{Concluding Remarks}

By exploring the relationship between return dispersion and return on the market, we document compelling evidence of herd behaviour in the Ho Chi Minh Stock Exchange (HOSE) of Vietnam between 2007 and 2015. As the market experiences large price movements, investors tend to dismiss their private belief and rashly follow other participants, thereby pushing stock prices in the same direction and lowering return dispersion. This is captured by negative coefficients for the relationships between dispersion and squared market return or with dummy variables representing "extreme" market conditions. The results are robust to daily price limit tests.

Tests for asymmetry herding in up vis-à-vis down market indicate that, consistent with other studies on herd behaviour in Asian markets, herding is stronger during periods of upward as opposed to downward movements. The asymmetry appears to have been driven by stocks with small market capitalisation. The magnitude of herding in the market seems to have significantly reduced following the global financial crisis, possibly due to improvements on the part of investors as they better equip themselves with knowledge, experience and more sophisticated trading strategies. The improvement appears more evident in the down market, which suggests investor optimism in market recovery and/or a growth in the proportion of long-term traders in the market. 
By improving upon Galariotis et al. (2015)'s approach of decomposing total cross-sectional absolute deviation (CSAD) into a component that can be explained by fundamental factors, and a component that cannot, we also document robust non-fundamental herding in the market when fundamental (or spurious) herding is factored out. Our approach of using the absolute values of the fundamental factors in the decomposition relates more closely the mathematical construction of CSAD and the factors, thus offering higher explanatory power.

The above empirical results contribute to the literature on testing stock market efficiency in emerging markets. Similar to other researches on Vietnam stock market such as Truong et al. (2007) and Metghalchi et al. (2013) both find significant profitability of momentum strategies and technical trading rules, this study suggests behaviour that is inconsistent with the assumption of investor rationality and efficient market hypothesis, and are indicative of market inefficiency. In addition, by relaxing the assumption of investor homogeneity and allowing both arbitrageurs and noise traders in the market, we find evidence of herding within each group, as well as interaction between them and thus reveal the possibility that arbitrageurs might take advantage of noise traders' positive feedback mentality and bring stocks even further away from their fundamental values to benefit from such herds.

Due to data constraints, we are unable to further investigate two issues. Firstly, we propose that the source of the herding asymmetry between the up and down markets could be small capitalisation stocks. We however could not carry the investigation further to reveal the underlying mechanism for this phenomenon due to data constraint. Secondly, we document evidence indicative of interactions between arbitrageurs and noise traders in the market, and in particular, how the former might have attempted to take advantage of the latter's herd mentality. As the available data does not permit more precise test or identification of each group's stockholdings, we are unable to conduct further investigation to confirm our conjecture. We agree that there might be other forces in place that result in the positive relationship between $R_{-m, t}^{2}$ and $C S A D_{+, t}$ documented in Table 10. We leave these issues for future studies. 
Several recommendations based on our findings are proposed with the aim of mitigating the effects of herd behaviour in the market. For investors, herding increases correlation among individual returns, which raises the need for a larger number of securities with low correlation to achieve the same level of diversification than in a market which does not exhibit herd mentality. For the government, the presence of herding signifies inadequacy of information for decisionmaking for investors, which in turn calls for additional requirements for better information, in terms of both quality and quantity, at both firm and industry levels. There should also be policies to attract foreign and institutional investors, who can help improve the stock market with their expertise and experience. These recommendations are also applicable to emerging markets and developing countries, where individuals are the key market participants and the financial regulation system is still largely in development. 


\section{References}

Admati, A. R., \& Pfleiderer P. (1997). Does it All Add Up? Benchmarks and the Compensation of Active Portfolio Managers. Journal of Business, 70, 323-350.

Andrews, D. W. K. (1993). Test for Parameter Stability and Structural Change with Unknown Change Point. Econometrica, 61, 821-856.

Banerjee, A. V. (1992). A Simple Model of Herd Behavior. Quarterly Journal of Economics, $107,797-817$.

Bikhchandani, S., Hirshleifer, D., \& Welch, I. (1992). A Theory of Fads, Fashion, Custom, and Cultural Change as Informational Cascades. Journal of Political Economy, 100, 992-1026.

Bikhchandani, S., Hirshleifer, D., \& Welch, I. (1998). Learning from the Behavior of Others: Conformity, Fads, and Informational Cascades. Journal of Economic Perspectives, 12, 151170.

Bikhchandani, S., \& Sharma, S. (2001). Herd Behavior in Financial Markets. IMF Staff Papers, 47, 279-310.

Black, F. (1986). Noise. Journal of Finance, 41, 529-543.

Bohl, M. T., Klein, A. C., \& Siklos, P. L. (2014). Short-selling Bans and Institutional Investors' Herding Behaviour: Evidence from the Global Financial Crisis. International Review of Financial Analysis, 33, 262-269.

Carhart, M. M., (1997). On Persistence in Mutual Fund Performance. Journal of Finance, 52, $57-82$.

Chang, E. C., Cheng, J. W., \& Khorana, A. (2000). An Examination of Herd Behaviour in Equity Markets: An International Perspective. Journal of Banking \& Finance, 24, 1651-1679.

Chiang, T. C., \& Zheng, D. (2010). An Empirical Analysis of Herd Behaviour in Global Stock Markets. Journal of Banking \& Finance, 34, 1911-1921.

Choi, J. J., Kedar-Levy, H., \& Yoo, S. S. (2015). Are Individual or Institutional Investors the Agents of Bubbles? Journal of International Money and Finance, 59, 1-22.

Christie, W. G., \& Huang, R. D. (1995). Following the Pied Piper: Do Individuals Returns Herd around the Market? Financial Analysts Journal, 51, 31-37.

De Long, J. B., Shleifer, A., Summers, L. H., \& Waldmann, R. J. (1990a). Positive Feedback Investment Strategies and Destabilizing Rational Speculation, Journal of Finance, 45, 379395.

De Long, J. B., Shleifer, A., Summers, L. H., \& Waldmann, R. J. (1990b). Noise Trader Risk in Financial Markets, Journal of Political Economy, 98, 703-738. 
Devenow, A., \& Welch, I. (1996). Rational Herding in Financial Economics. European Economic Review, 40, 603-615.

Dickey, D. A., \& Fuller, W. A. (1979). Distribution of the Estimators for Autoregressive Time Series with a Unit Root. Journal of the American Statistical Association, 74, 427-431.

Fama, E. F. (1970) Efficient Capital Markets: A Review of Theory and Empirical Work. Journal of Finance, 25, 383-417.

Fama, E. F., \& French, K. R. (1995). Size and Book-to-Market Factors in Earnings and Returns. The Journal of Finance, 50, 131-155.

Fama, E. F., \& French, K. R. (1996). Multifactor Explanations of Asset Pricing Anomalies. Journal of Finance, 51, 55-84.

Frey, S., Herbst, P., \& Walter, A. (2014). Measuring Mutual Fund Herding - A Structural Approach. Journal of International Financial Markets, Institutions \& Money, 32, 219-239.

Galariotis, E. C., Rong, W., \& Spyrou, S. I. (2015). Herding on Fundamental Information: A Comparative Study. Journal of Banking \& Finance, 50, 589-598.

Graham, J. R. (1999). Herding among Investment Newsletters: Theory and Evidence. The Journal of Finance, 54, 237-268.

Grinblatt, M., Titman, S., \& Wermers, R. (1995). Momentum Investment Strategies, Portfolio Performance, and Herding: A Study of Mutual Fund Behavior. The American Economic Review, 85, 1088-1105.

Hoang Vu (2013). Changes to the Daily Price Limits and Effects on the Stock Market. Vietstock. Retrieved from Vietstock website http://vietstock.vn/2013/01/thay-doi-bien-do-giao-dich-vatac-dong-den-ttck-830-254005.htm.

Hwang, E., Min, H., Kim, B., \& Kim H. (2013). Determinants of Stock Market Comovements Among US and Emerging Economies during the US Financial Crisis. Economic Modelling, $35,338-348$.

Jensen, M. C. (1968). The Performance of Mutual Funds in the Period 1945-1964. The Journal of Finance, 23, 389-416.

Lakonishok, J., Shleifer, A., \& Vishny, R. W. (1992). The Impact of Institutional Trading on Stock Prices. Journal of Financial Economics, 32, 23-43.

Liew, J., \& Vassalou, M. (2000). Can Book-to-Market, Size and Momentum be Risk Factors that Predict Economic Growth? Journal of Financial Economics, 57, 221-245.

Metghalchi, M., Hajilee, M., \& Hayes, L. A. (2013). Market Efficiency and Profitability of Technical Trading Rules: Evidence from Vietnam. Journal of Prediction Markets, 7, 11-27. 
McQueen, G., Pinegar, M., \& Thorley, S. (1996). Delayed Reaction Good News and the CrossAutocorrelation of Portfolio Returns, Journal of Finance, 51, 889-919.

Prendergast, C., \& Stole, L. (1996). Impetuous Youngsters and Jaded Old-Timers: Acquiring a Reputation for Learning. Journal of Political Economy, 104, 1105-1134.

Quandt, R. E. (1960). Test of the Hypothesis that a Linear Regression System Obeys Two Separate Regimes. Journal of the American Statistical Association, 55, 324-330.

Rajan, R. G. (2006). Has Finance Made the World Riskier? European Financial Management, $12,499-533$.

Scharfstein, D. S., \& Stein J. C. (1990). Herd Behavior and Investment. American Economic Review, 80, 465-479.

Shaffer, L. (2014). Will Vietnam Stocks Resume Their Rally in 2015? CNBC. Retrieved from CNBC website: http:/www.cnbc.com/2014/12/09/will-vietnam-stocks-resume-their-rally-in2015.html.

Shleifer, A., \& Summers, L. H. (1990). The Noise Trader Approach to Finance. Journal of Economic Perspectives, 4, 19-33.

Spyrou, S. (2013). Herding in Financial Markets: A Review of the Literature. Review of Behavioural Finance, 5, 175-194.

Stock, J. H., \& Watson, M. W. (2011). Introduction to Econometrics. (3rd ed). Pearson.

Trueman, B. (1994). Analyst Forecasts and Herding Behavior. The Review of Financial Studies, 7, 97-124.

Truong, C., Veeraraghavan, M., \& Nguyen, M. T. T. (2007). Delayed Price Discovery and Momentum Strategies: Evidence from Vietnam. Working Paper, Department of Accounting \& Finance, Faculty of Business \& Economics, Monash University.

Venezia, I., Nashikkar, A., \& Shapira, Z. (2011). Firm Specific and Macro Herding by Professional and Amateur Investors and their Effects on Market Volatility. Journal of Banking \& Finance, 35, 1599-1609.

Villatoro, F. (2009). The Delegated Portfolio Management Problem: Reputation and Herding. Journal of Banking \& Finance, 33, 2062-2069.

Welch, I. (1992). Sequential Sales, Learning and Cascades. Journal of Finance, 47, 695-732.

Wermers, R. (1999). Mutual Fund Herding and the Impact on Stock Prices. Journal of Finance, $54,581-622$.

Zwiebel, J. (1995). Corporate Conservatism and Relative Compensation. Journal of Political Economy, 103, 1-25. 


\section{Appendix A: Data Clean-up}

The data are subject to a number of adjustments. Firstly, there exist weekdays during the period in which there was no trading (due to public holidays taking place or technical difficulties). Datastream typically enters the same data for these days as the closest previous trading day. All such values are removed prior to computation of returns.

Secondly, it is not uncommon for stocks to be delisted or moved from one exchange to another. As such, price series for several stocks are truncated so that only the data pertaining to the period in which the stocks were listed on HOSE are considered. Table A.1 reports the cut-off dates for stocks originally on another exchange started being traded on HOSE, while Table (ii) presents the cut-off dates for stocks which were delisted from the HOSE. The dates are provided by Datastream (for dead stocks) and the Vietnam Securities Depository (VSD) (2015) (for stocks delisted due to failure to meet HOSE listing requirements or stocks moved to other exchanges).

Table A.1

Stock Commencement Dates on HOSE.

\begin{tabular}{cccc}
\hline Stocks & $\begin{array}{c}\text { HOSE Trade } \\
\text { Commencement } \\
\text { Date }\end{array}$ & Stocks & $\begin{array}{c}\text { HOSE Trade } \\
\text { Commencement } \\
\text { Date }\end{array}$ \\
\hline CDC & $10 / 09 / 2010$ & TCO & $20 / 12 / 2011$ \\
PAN & $14 / 12 / 2010$ & SVI & $15 / 03 / 2012$ \\
ACC & $29 / 06 / 2011$ & C32 & $30 / 11 / 2012$ \\
PDN & $29 / 08 / 2011$ & FLC & $02 / 08 / 2013$ \\
HU1 & $02 / 11 / 2011$ & MWG & $11 / 07 / 2014$ \\
ITD & $20 / 12 / 2011$ & SHP & $18 / 07 / 2014$ \\
\hline
\end{tabular}

Source: Summarised by the author from VSD (2015). 


\section{Table A.2}

Delisting Dates of Former HOSE Stocks.

\begin{tabular}{cccc}
\hline Stocks & HOSE Delisting Date & Stocks & HOSE Delisting Date \\
\hline BBT & $07 / 08 / 2009$ & NTB & $26 / 07 / 2013$ \\
FPC & $11 / 08 / 2011$ & AGD & $28 / 08 / 2013$ \\
DVD & $05 / 09 / 2011$ & CLP & $15 / 05 / 2014$ \\
DCC & $15 / 12 / 2011$ & FDG & $15 / 05 / 2014$ \\
TRI & $10 / 04 / 2012$ & PXM & $20 / 05 / 2014$ \\
MCV & $11 / 05 / 2012$ & CNT & $20 / 05 / 2014$ \\
CAD & ALP & $31 / 12 / 2014$ \\
MKP & $06 / 06 / 2012$ & SBC & $12 / 02 / 2015$ \\
CSG & $12 / 07 / 2012$ & HLA & $25 / 02 / 2015$ \\
BAS & $04 / 10 / 2012$ & NHW & $25 / 02 / 2015$ \\
VFC & $08 / 10 / 2012$ & MPC & $31 / 03 / 2015$ \\
DDM & $05 / 02 / 2013$ & HIS & $04 / 05 / 2015$ \\
IFS & $15 / 04 / 2013$ & VNI & $05 / 05 / 2015$ \\
VSG & $03 / 05 / 2013$ & NVN & $05 / 05 / 2015$ \\
VES & $07 / 05 / 2013$ & DCT & $08 / 05 / 2015$ \\
FBT & $07 / 05 / 2013$ & VST & $13 / 05 / 2015$ \\
\hline
\end{tabular}

Source: Summarised by the author from VSD (2015) and Datastream.

Thirdly, prices of numerous stocks on 22 April 2013, as reported by Datastream, appear to be highly unusual. Prices might jump (drop) sharply 19 April (Friday) to 22 April (Monday), followed by a comparably sharp drop (jump) between the 22 April and 23 April (illustrated in Table A.3 below). This is possibly due to errors made by the data provider. As a precaution, all observations for 22 April 2013 are dropped. 


\section{Table A.3}

Stock Prices on 19, 22 and 23 April 2013 Reported by Datastream.

\begin{tabular}{cccc}
\hline & \multicolumn{3}{c}{ Prices (Vietnam Dong) } \\
\cline { 2 - 4 } Stocks & $\mathbf{1 9}$ April 2013 & 22 April 2013 & $\mathbf{2 3}$ April 2013 \\
\hline FPT & 25,739 & $\mathbf{1 4 , 9 5 7}$ & 25,948 \\
MBB & 12,264 & $\mathbf{4 , 7 9 1}$ & 12,360 \\
HAG & 20,091 & $\mathbf{5 , 4 5 5}$ & 19,273 \\
JVC & 13,496 & $\mathbf{7 , 4 7 2}$ & 13,725 \\
KDC & 40,416 & $\mathbf{5 , 1 6 7}$ & 39,583 \\
KBC & 6,300 & $\mathbf{1 0 , 2 0 0}$ & 6,300 \\
NBB & 12,864 & $\mathbf{3 , 9 6 3}$ & 12,577 \\
TCL & 20,500 & $\mathbf{1 5 , 8 0 0}$ & 20,300 \\
GTT & 11,200 & $\mathbf{4 , 9 0 0}$ & 11,200 \\
VHG & 2,400 & $\mathbf{1 1 , 1 3 3}$ & 2,200 \\
\hline
\end{tabular}

Source: Summarised by the author from Datastream. 